Images Re-vues

re-VuES

Histoire, anthropologie et théorie de l'art

9| 2011

Parenté en images

\title{
Génération Crivelli
}

Crivelli Generation

\section{Thomas Golsenne}

\section{(2) OpenEdition}

Journals

Édition électronique

URL : http://journals.openedition.org/imagesrevues/1646

DOI : 10.4000/imagesrevues. 1646

ISSN : 1778-3801

\section{Éditeur :}

Centre d'Histoire et Théorie des Arts, Groupe d'Anthropologie Historique de l'Occident Médiéval, Laboratoire d'Anthropologie Sociale, UMR 8210 Anthropologie et Histoire des Mondes Antiques

Référence électronique

Thomas Golsenne, «Génération Crivelli », Images Re-vues [En ligne], 9 | 2011, mis en ligne le 01 janvier 2011, consulté le 31 janvier 2021. URL : http://journals.openedition.org/imagesrevues/1646 ; DOI : https://doi.org/10.4000/imagesrevues.1646

Ce document a été généré automatiquement le 31 janvier 2021.

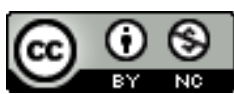

Images Re-vues est mise à disposition selon les termes de la Licence Creative Commons Attribution Pas d'Utilisation Commerciale 4.0 International. 


\section{Génération Crivelli}

Crivelli Generation

Thomas Golsenne

Filiation, alliance, création 
1 C'est dans leur définition du devenir que Gilles Deleuze et Félix Guattari en viennent à opposer la filiation et l'alliance.

«[...] devenir n'est pas une évolution, du moins une évolution par descendance et filiation. Le devenir ne produit rien par filiation, toute filiation serait imaginaire. Le devenir est toujours d'un autre ordre que celui de la filiation. Il est de l'alliance. Si l'évolution comporte de véritables devenirs, c'est dans le vaste domaine des symbioses qui met en jeu des êtres d'échelles et de règnes tout à fait différents, sans aucune filiation possible. $»^{1}$

2 Que la peinture de Carlo Crivelli relève d'un art des symbioses, de l'alliance et du devenir, c'est ce que je m'emploierai à démontrer bientôt. Mais ne sautons pas les étapes. Une explication de la théorie

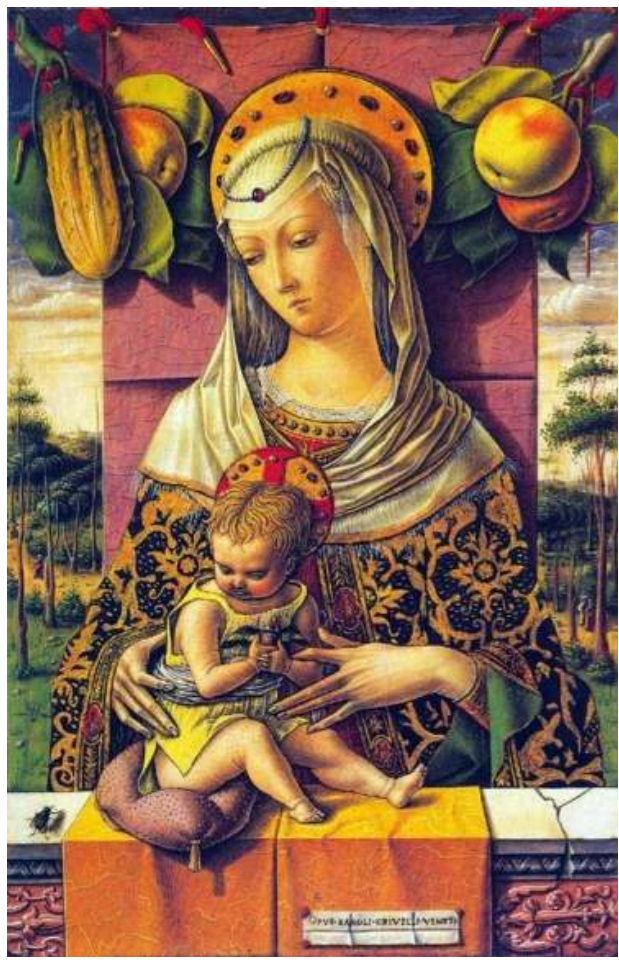
exposée par Deleuze et Guattari s'impose d'abord. En bons émules de Bergson ${ }^{2}$, les deux «pop-philosophes » opposent l'être et le devenir. D'un côté, une philosophie de l'être, celle de Platon, de Descartes, de Kant, où le rôle du philosophe consiste à définir l'être stable des étants, leur définition universelle, leur identité propre; bref, le domaine du philosophe de l'être, c'est celui de ce qui ne change pas, de ce qui est toujours identique à soi-même, unique. D'un autre côté, une philosophie du devenir, celle d'Héraclite, de Montaigne, de Bergson, où le philosophe s'emploie au contraire à découvrir, derrière l'apparente immobilité des choses, leur réelle transformation continue, tel le fleuve héraclitéen, toujours identique et pourtant toujours différent. Dans cette philosophie, tout change, car tout existe dans le temps qui fait tout changer. À l'inverse la philosophie de l'être est atemporelle, pensée pour Dieu et l'éternités.

3 Penser le devenir en termes d'évolution comme filiation est donc une erreur. En effet le modèle de la filiation implique la reproduction d'un schéma identitaire, héréditaire, au long des générations: c'est l'arbre généalogique, qui permet de remonter jusqu'à l'origine d'une lignée, de trouver les points de ressemblance entre les membres d'une famille (que cela soit la famille des Médicis ou celle des dinosaures). L'idée que les enfants ressemblent aux parents est une conviction naturelle encore aujourd'hui ; elle est pourtant entièrement le fruit d'une construction culturelle, comme l'avait déjà supposé Montaigne ${ }^{4}$ et comme les spécialistes de la parenté l'expliquent ${ }^{5}$. Cette construction remonte, en Europe, à Aristote. Dans De la génération des animaux, Aristote énonce clairement le lien entre filiation et ressemblance: le principe de base de la génération des animaux est homogénique. Le mâle (porteur de la « forme " générale de l'espèce) transmet les caractères de son espèce (ce qui la définit en tant qu'espèce singulière, ce qui fait son identité) à sa progéniture, d'où une ressemblance générique entre les individus au sein d'une même espèce. On est reconduit finalement à un principe d'identité : l'engendrant et l'engendré sont synonymes, l'homme engendre l'homme. Les différences individuelles que l'on observe ne remettent pas en cause le 
principe général de ressemblance spécifique: elles sont provoquées, comme les ressemblances particulières d'ailleurs (la couleur des yeux, les marques sur la peau etc.), par la résistance de la matière, par la qualité du sang masculin (transmis dans le sperme) et du sang féminin (actif dans les menstrues). Si bien que pour Aristote, toute différence n'est qu'une infraction à la règle, le plus souvent produite par la faiblesse du sperme masculin (source de ressemblance) et la résistance du sang féminin (source de dissemblance) - le cas extrême étant représenté par les rejetons d'unions interspécifiques ou par les produits de la génération spontanée qui, ne pouvant reproduire à l'identique les caractères spécifiques de leur forme paternelle, sont voués à la différence et à la stérilité 6 .

4 La ressemblance maternelle s'explique comme une résistance de la matière face à la forme paternelle. Ce processus est exactement celui par lequel Aristote décrit le travail de tout fabricant, architecte, cordonnier, sculpteur: celui-ci a une forme dans l'esprit qu'il cherche à imprimer dans la matière ${ }^{7}$. On a ici le noyau de la relation entre création artistique et ressemblance généalogique. Pendant plusieurs siècles, les auteurs reprenant Aristote trouveront dans les théories du Stagirite une confirmation de leur vision sexiste des relations matrimoniales, en insistant sur le fait que la bonne ressemblance est celle du père au fils, et que c'est la mère qui est, sauf exception ${ }^{8}$, toujours la cause de la dissemblance (notamment via l'adultère).

5 La généalogie ou le modèle de l'arbre servent à classer ce qui se ressemble et à le ramener à un principe unique. Ils permettent difficilement de comprendre, de façon interne, comment la différenciation apparaît le long de la généalogie (car comment produire du différent à partir de l'identique ?). Il faut bien admettre alors une instance extérieure qui introduit la nouveauté, qui fait différer l'identique. D'où le modèle, choisi par Deleuze et Guattari pour penser le devenir, de l'alliance. C'est l'avoisinement de plusieurs êtres hétérogènes, c'est l'introduction de l'autre dans le même par le dehors qui définit le devenir. Devenir, c'est différer, c'est se mêler. Trouver qui on est, c'est trouver son identité ; trouver ce qu'on devient, c'est découvrir la multiplicité qui est en soi et hors de soi. La famille est du côté de l'être; du côté du devenir il y a la bande, la meute. À l'ancêtre tutélaire, au paterfamilias s'oppose le chef de bande, qui en occupe la bordure, là où s'opère l'ouverture vers le dehors.

$6 *$

7 Cette opposition métaphysique entre Bergson et Aristote, le devenir et l'être, n'aurait rien à faire dans un article d'histoire de l'art si elle ne comportait une implication esthétique. En effet, aux yeux de Deleuze et Guattari, et avant eux de Bergson, seule la philosophie du devenir permet de penser réellement la création. La philosophie de l'être cherche à remonter le temps : derrière les phénomènes, des essences, des causes, jusqu'à remonter à la première, le Premier Moteur, l'Un, l'Être toujours identique à luimême. Créer, dans ce cadre, ne se dit que pour Dieu (l'Être unique) qui est lui-même incréé : autant dire qu'il y a quelque chose de supérieur à la création elle-même, dans l'ordre de la transcendance. Mais la philosophie du devenir va toujours de l'avant: le devenir emporte tout ce qui existe avec lui, le fait changer, selon un mouvement imprévisible. Exemple bergsonien : je peux imaginer la réunion de travail de demain parce que j'en ai fait une dans des conditions similaires hier; mais entre cette image que j'anticipe et la réunion telle que je vais la vivre, il y aura une différence, peut-être imperceptible, mais qui fera précisément que cette réunion existe en dehors de mon imagination, et qui tiendra à mon état de fatigue ou de fraîcheur, à ce que j'aurai mangé 
le midi, à l'état de mes collègues, au temps qu'il fait etc..$^{9}$ Une image qu'au xvi ${ }^{\mathrm{e}}$ siècle, un Montaigne pouvait déjà trouver chez Plutarque : tel homme invité pour le lendemain à un dîner, trouve la porte fermée quand le moment du dîner arrive: il n'est plus l'homme qui avait été invité ${ }^{10}$.

L'intelligence, ajoute Bergson, est capable de créer des découpes dans le réel, dans le devenir, des images statiques, qu'elle peut ensuite comparer pour ensuite choisir le comportement approprié: l'intelligence cherche des ressemblances entre les phénomènes, c'est-à-dire rapporte du différent à du semblable, de l'inconnu à du connu, pour le maîtriser. Ainsi procède l'intelligence métaphysique, qui croit toucher à l'être réel des choses parce qu'elle lui trouve une identité parfaite avec son essence, alors qu'elle n'a ainsi fabriqué qu'une image parfaitement abstraite du réel. Au contraire, le philosophe, selon Bergson, devrait sentir le réel, c'est-à-dire accorder sa conscience au rythme du monde, percevoir le devenir des choses, qui passe entre les images. Car à ce niveau, dit-il, on se rend compte que le monde et ce qui le compose est une formidable source de création continue: en effet, toujours quelque chose de nouveau apparait, toujours quelque chose d'inédit, non pas à partir de rien, mais à partir de ce qui existait avant. Voir le monde de cette façon, avec la curiosité d'un enfant ou d'un voyageur pour qui tout ce qui est nouveau est bon et beau, c'est déjà se préparer à être créateur soi-même. C'est pourquoi les artistes, pour Bergson, sont beaucoup mieux que les philosophes aptes à guider l'humanité dans cette voie :

« Le Temps est immédiatement donné. Cela nous suffit, et, en attendant qu'on nous démontre son inexistence ou sa perversité, nous constaterons simplement qu'il y a jaillissement effectif de nouveauté imprévisible.

La philosophie y gagnera de trouver quelque absolu dans le monde mouvant des phénomènes. Mais nous y gagnerons aussi de nous sentir plus joyeux et plus forts. Plus joyeux, parce que la réalité qui s'invente sous nos yeux donnera à chacun de nous, sans cesse, certaines des satisfactions que l'art procure de loin en loin aux privilégiés de la fortune ; elle nous découvrira, par delà la fixité et la monotonie qu'y apercevaient d'abord nos sens hypnotisés par la constance de nos besoins, la nouveauté sans cesse renaissante, la mouvante originalité des choses. Mais nous serons surtout plus forts, car à la grande œuvre de création qui est à l'origine et qui se poursuit sous nos yeux nous nous sentirons participer, créateurs de nousmêmes. " ${ }^{11}$

\section{La peinture adultère}

9 L'alliance, c'est la symbiose de deux corps hétérogènes pour en former un troisième, plus fort : une hétérogenèse. Sans alliance, si l'on suit la définition deleuzienne, nulle création n'est possible, dans la mesure où la création repose, sur l'apparition du nouveau, du différent. On crée quand on devient autre. Pour Deleuze et Guattari, l'authentique création s'effectue toujours par adjonction de parties extérieures, comme dans le patchwork - non pas par amplification d'un noyau central (modèle aristotélicien de la forme en puissance dans la matière) mais par production de liens, de passages, d'associations entre des points de passage. Un artiste qui suit ce schéma de développement "rhizomatique " est forcément nomade, sans racines, sans tradition d'où il puise son style. Il développe ce dernier au fur et à mesure de ses pérégrinations, par des rencontres avec d'autres artistes. Son style personnel est l'accumulation, l'ensemble de ces rencontres qu'il incorpore et combine de façon originale. Chaque 
rencontre est une alliance que l'artiste noue avec un artiste extérieur, une façon de multiplier la différenciation.

Curieusement, l'histoire de l'art - comme discours humaniste, comme discipline universitaire - a eu tendance à privilégier les artistes sédentaires ; artistes s'inscrivant dans une tradition locale, artistes dont on qualifie le style de "florentin » ou de "vénitien " parce qu'il ressemble au style dominant dans ces contrées. Le vaste récit inaugural de Vasari est identitaire : il articule une maniera à une communauté et à un territoire. Le succès de tel ou tel artiste est déterminé en bonne partie par la façon dont il s'inscrit dans cette identité locale et stylistique. Dans la Préface générale aux Vies, Vasari énonce sans ambages: « Pourtant les esprits de la nouvelle génération, favorisés par la qualité de l'atmosphère, se dégagèrent si bien qu'en 1250, le ciel, touché par les beaux talents quotidiennement issus de la terre toscane, leur rendit leurs aptitudes primordiales. $»^{12}$ Les historiens de l'art postérieurs à Vasari ont fidèlement repris cet esprit identitaire et ce découpage territorial de l'art italien en centrant leurs ouvrages sur l'art à Bologne, l'art à Rome, l'art à Florence, l'art à Venise etc. ${ }^{13}$

11 La tradition des ateliers, la segmentation territoriale de l'Italie avant l'unification du XIX ${ }^{e}$ siècle, l'habitude de transmettre le métier de père en fils (Vasari cite plusieurs «dynasties » de peintres, les Gaddi, les Lippi, les Bellini...) peuvent justifier ce choix épistémologique. Chez l'auteur arétin, de la transmission biologique entre le père et le fils on passe souvent à la transmission artistique du maitre à l'élève. Dans la Vie de Cimabue, il écrit que Giotto est "issu » de Cimabue, "suo creato », ce qui, dans l'italien $\mathrm{du} \mathrm{XVI}^{\mathrm{e}}$ siècle, peut signifier "son élève» ou bien "engendré par lui, né de lui » ${ }^{14}$. L'invention d'une parenté artistique par Vasari se décline ensuite au fil des Vies, quoique de manière parfois surprenante. Un exemple intéressant est donné par la Vie de Tommaso Fiorentino, dit Giottino: biographie imaginaire d'un successeur de Giotto idéal, inventeur de la «manière douce » que les plus grands peintres des générations suivantes adopteront à leur tour. Or, ce " petit Giotto ", écrit Vasari,

« décida d'imiter au maximum, avec un grand zèle, la manière de Giotto plutôt que celle de son père Stefano. Il le fit si bien qu'il y gagna, en plus d'un style bien supérieur à celui de son maître, le surnom de Giottino qui ne le quitta jamais. Beaucoup crurent même, de par son style comme de par son nom, qu'il était le fils de Giotto ; ce qui est une grave erreur. ${ }^{15}$

12 Contre la parenté biologique, la parenté artistique ; contre la ressemblance innée, la ressemblance acquise par l'imitation, qui garantit la pérennité du bon style florentin et assure en même temps sa transmission ${ }^{16}$. Il y a dans cet écart un problème que la seule lecture des Vies vasariennes et de ses références humanistes ne permet pas de résoudre; on y reviendra.

13 Le modèle territorial domine néanmoins le récit vasarien. Mais la vie des artistes ne respecte pas toujours le territorialisme auquel les historiens voudraient bien les restreindre. Bon nombre d'entre eux - et des meilleurs - sont problématiques parce qu'ils n'ont cessé de se déplacer. Quasi nomades, ils développent un style qui échappe à un ancrage territorial, au respect d'une tradition locale. Alors éclate le modèle généalogique. Chez Vasari, le récit de ces vies de nomades est toujours intéressant, car révélateur des stratégies narratives par lesquelles il essaye de les incorporer à son schéma territorialiste. Souvent donc, le nomadisme des artistes est la cause de leurs échecs. Ainsi Léonard, trop instable, incapable d'achever quoique ce soit, ou Rosso Fiorentino, errant depuis le Sac de Rome, finissant sa vie d'exilé par un suicide, en 
France. André Chastel avait remarqué également comment Vasari interprétait les fortunes et les misères de Michel-Ange selon qu'il respirait le bon « air » de sa Toscane natale ou pas ${ }^{17}$. Il y a évidemment des exceptions positives, et non des moindres, comme Raphaël, dont la carrière est décrite par Vasari comme un passage de ville en ville et de maître en maître (son propre père à Urbino, puis Pietro Perugino à Pérouse, Léonard à Florence, Michel-Ange à Rome ${ }^{18}$ ), jusqu'à devenir lui-même un maître, bien installé à Rome, fondateur d'un atelier florissant. En d'autres termes, Vasari réussit à décrire la carrière de Raphaël comme s'il avait raccroché en cours de route le train de la tradition florentine pour finalement le diriger. Mais on pourrait dire tout autrement que c'est précisément en s'écartant du modèle toscan que Raphaël a trouvé sa propre manière...

14 Une histoire des artistes nomades reste à faire. Comment l'écrire, suivant quel modèle? Le mérite du modèle vasarien est d'avoir su trouver une formule qui permette de réunir une collection d'individualités très disparates en un tout organique: le schéma ontogénétique des trois âges des arts du dessin ${ }^{19}$. Mais ce modèle, généalogique, fondé sur l'idée de transmission stylistique par filiation locale, est inapplicable aux artistes nomades. Il faut donc penser l'histoire des rapports entre ces artistes en partant d'un autre modèle. Peut-être celui forgé par Henri Focillon et plus guère employé, car quelque peu anachronique, des «familles spirituelles»:

«Il existe une sorte d'ethnographie spirituelle qui s'entrecroise à travers les "races" les mieux définies, des familles d'esprits unies par des liens secrets et qui se retrouvent avec constance par delà les temps, par delà les lieux. Peut-être chaque style et chaque état d'un style, peut-être chaque technique requièrent-ils de préférence telle nature d'homme, telle famille spirituelle. $»^{20}$

On retrouverait ainsi, chez les grands artistes nomades, Raphaël, le Greco, Caravage... des traits communs, qu'une analyse comparative structurelle permettrait peut-être de relever. Gageons que l'éclectisme des sources d'inspiration ou l'alliage des formes figureraient parmi ces caractéristiques communes. Or cette "famille» d'artistes nomades, si minoritaire qu'elle paraisse au regard de l'histoire de l'art traditionnelle, occuperait, dans une esthétique inspirée de Deleuze et Guattari, une place de premier plan. Car, si l'on accepte leur théorie, seule une esthétique de l'alliage ou de la symbiose est une esthétique authentique du devenir, c'est-à-dire de la création. Mais ces artistes ont souvent produit à leur tour un mouvement d'imitation, une volonté de ressemblance irrésistibles auprès d'autres peintres qu'on a bien du comparer à des «familles » stylistiques (les « caravagesques »...). Ce phénomène fait-il encore partie du mouvement nomade initié par le peintre qui en est à l'origine, relève-t-il encore de l'alliance ? Ou doit-il être interprété comme un mouvement de "reterritorialisation ", de retour à un mode de filiation généalogique d'où toute création authentique serait exclue?

L'exemple de Crivelli peut servir de bon laboratoire pour répondre à une telle question. D'une part, son absence dans les Vies de Vasari peut être perçue comme un symptôme : Crivelli était trop loin du modèle biographique, géographique, généalogique, qui structurait l'histoire de l'art vasarienne. Et les historiens de l'art postérieurs qui ont étudié Crivelli d'un point de vue vasarien, c'est-à-dire localiste (Crivelli comme chef d'une école de peinture dans la Marche d'Ancône ${ }^{21}$ ), ont fait fausse route : il vaut mieux, c'est là mon hypothèse, l'étudier d'abord pour son nomadisme. Le développement de la 
peinture de Crivelli est en effet exemplaire de ce phénomène de création par alliance, au moins dans sa première phase - on va le voir dans un instant.

Mais, d'autre part, dans sa seconde phase la peinture de Crivelli suscite un mouvement d'imitation auprès des peintres de la Marche d'Ancône, d'une portée assez incroyable : tous, depuis ses plus proches disciples jusqu'au plus modeste barbouilleur de paese marchisan, crivellisent pendant une trentaine d'années. Tout se passe comme si le peintre nomade s'était finalement attaché à un territoire et comme si sa peinture était rentrée dans le modèle de la filiation locale. En somme, la carrière de Crivelli fournirait un observatoire miniature de l'opposition esthétique entre filiation et alliance. Son analyse permettra de mettre à l'épreuve ce paradigme philosophique - et de le nuancer fortement.

Quelques rappels ${ }^{22}$. Crivelli est issu d'une famille de peintres, comme beaucoup d'autres Vénitiens de son temps : les Vivarini, les Bellini. Mais de son père on ne sait rien (sauf qu'il était peintre); et de son frère cadet, Vittore, on ne voit généralement en lui qu'un mauvais copiste de son ainé (je reviendrai plus tard sur cette question et sur ce frère). Contrairement aux Vivarini ou aux Bellini, Crivelli semble avoir vite rompu avec l'atelier paternel. On pourrait interpréter en la forçant un peu une anecdote de sa jeunesse comme une indication de sa résistance au modèle généalogique. Il fut condamné à Venise à six mois de prison en 1457 pour avoir enlevé la femme d'un marin. Comme si l'alliance ne pouvait se concevoir que sous la forme d'une violence, en ses jeunes années. Or Hugues de Saint-Victor au $\mathrm{XII}^{\mathrm{e}}$ siècle avait justement qualifié la création humaine d'adultère : elle était à ses yeux illégitime, comparée à la création naturelle ${ }^{23}$. Proposons ceci : l'art pour Crivelli sera adultère, alliance volée, rapt de formes.

Hugues de Saint-Victor ajoutait : l'art humain est adultère car il est mécanique, il est mécanique car il est adultère ( Mécanique, dit Edgar De Bruyne, est apparenté à moechari, ce qui signifie commettre l'adultère. »). Il est donc inférieur à la science ou aux arts libéraux, qui sont activités de l'âme. Nous dirons: Crivelli revendique la peinture comme art mécanique, artisanal, qui part de la matière plutôt que de l'esprit. Bien éloignée des milieux humanistes florentins, ferrarais ou mantouans où les peintres reçoivent des lettrés des titres de dignité intellectuelle, la peinture de Crivelli, pour être comprise, ne doit pas se soumettre aux préceptes du De pictura d'Alberti ou aux normes savantes du travail de Mantegna - c'est-à-dire qu'elle ne doit pas se soumettre à l'ordre du discours, au diktat de la poésie, à l'apanage du disegno. Ce n'est pas un art du projet mais un art du bricolage, au sens fort que lui donne Lévi-Strauss dans La pensée sauvage:

« Le bricoleur est apte à exécuter un grand nombre de tâches diversifiées ; mais, à la différence de l'ingénieur, il ne subordonne pas chacune d'elles à l'obtention de matières premières et d'outils conçus procurés à la mesure de son projet: son univers instrumental est clos, et la règle de son jeu est de toujours s'arranger avec les "moyens du bord", c'est-à-dire un ensemble à chaque instant fini d'outils et de matériaux, hétéroclites au surplus, parce que la composition de l'ensemble n'est pas en rapport avec le projet du moment, ni d'ailleurs avec aucun projet particulier, mais est le résultat contingent de toutes les occasions qui se sont présentées de renouveler ou d'enrichir le stock, ou de l'entretenir avec les résidus de constructions et de destructions antérieures. L'ensemble des moyens du bricoleur n'est donc pas définissable par un projet (ce qui supposerait d'ailleurs, comme chez l'ingénieur, l'existence d'autant d'ensembles instrumentaux que de genres de projets, au moins en théorie); il se définit seulement par son instrumentalité, 
autrement dit, et pour employer le langage même du bricoleur, parce que les éléments sont recueillis ou conservés en vertu du principe que "ça peut toujours servir". ${ }^{24}$ sont les motifs, les formes qu'il puise dans les différentes contrées qu'il traverse. Crivelli est un nomade bricoleur et glaneur dont les déplacements incessants de déraciné lui ont permis d'inventer un style tout personnel mais composé de multiples emprunts.

outons que la théorie du bricolage trouve un fort écho à son époque, par exemple chez Alberti. Dans son De profugiorum ab aerumna, le Florentin raconte en effet (par l'intermédiaire de l'un des personnages de son dialogue) que le poète ou le philosophe sont comme cet architecte qui inventa la mosaïque: il récupéra les restes de la décoration somptueuse des murs et du plafond d'un temple et, de ces débris, forma une image pour décorer le sol. Ainsi les poètes et les philosophes composent-ils leurs discours à partir de sources qu'ils ont récupérées : l'invention ne consiste pas dans la production de nouvelles idées, mais dans la composition originale d'idées anciennes ${ }^{25}$. D'où ce dicton, plusieurs fois cité par Alberti : « Rien n'est dit qui n'ait jamais été dit ».

Crivelli a-t-il purgé sa peine à l'issue de sa condamnation de 1457 ? On ne sait pas ; on ne conserve aucune œuvre d'importance signée de lui à Venise ; on perd définitivement sa trace dans la cité des Doges après cet épisode. Il ne reviendra plus jamais à Venise, comme si la faute originelle l'avait entrainé à fuir sa patrie et à trouver meilleure fortune en dehors du milieu vénitien.

Fig. 1

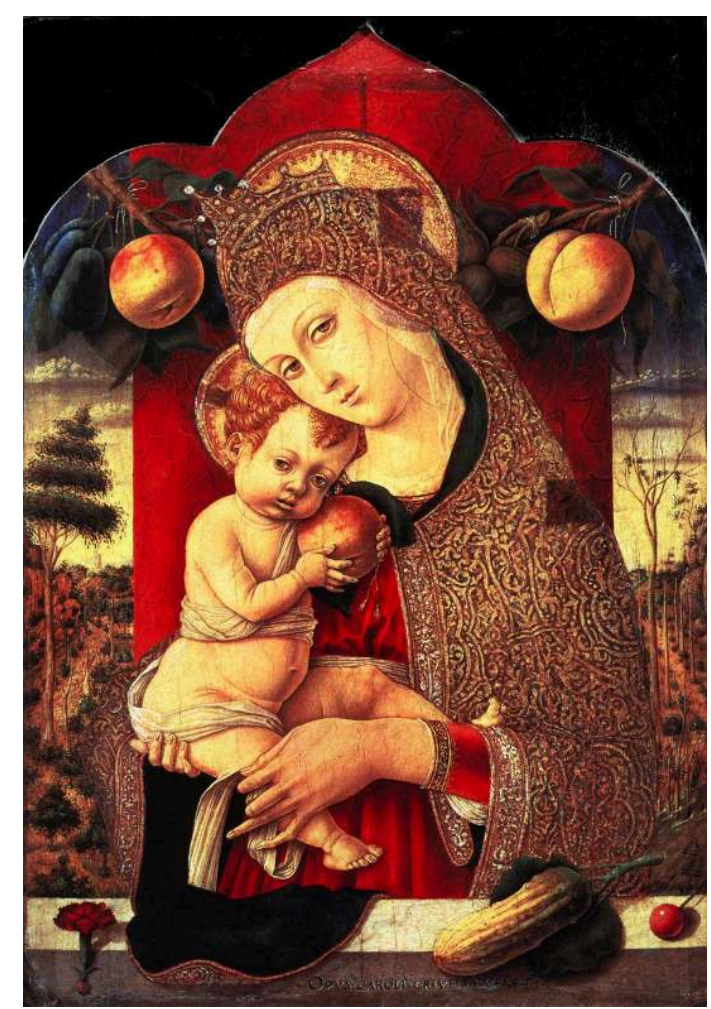

Carlo Crivelli, Vierge à l'Enfant, 1470-80, détrempe sur bois, 33 × 45 cm, Bergame, Accademia Carrara. DR 
Pourtant ses attaches à la peinture vénitienne sont importantes : il multiplie, comme Giovanni Bellini par exemple, les Vierge à l'Enfant devant un paysage, et les références à l'art byzantin, comme le manteau de métal de la Vierge du tableau de Bergame (fig. 1) ; comme les Vivarini, il excelle dans les ancone, ces grands polyptyques verticaux au cadre gothique (fig. 2). Mais la peinture vénitienne, dans la seconde moitié du Quattrocento, a de multiples visages : gothique, byzantin, archaïque, moderne. Elle se cherche, elle ne peut pas encore se définir, comme au Cinquecento, par un principe esthétique unique (le colorito). On dira donc que de son origine vénitienne, Crivelli tire surtout une pluralité de sources artistiques. Et une certaine fierté commerciale: il signera tous ses tableaux "venetus", un peu comme un grand couturier marque, en dessous de son nom, "Paris ». Mais c'est aussi que sa production fut sans doute celle d'un immigré.

Fig. 2

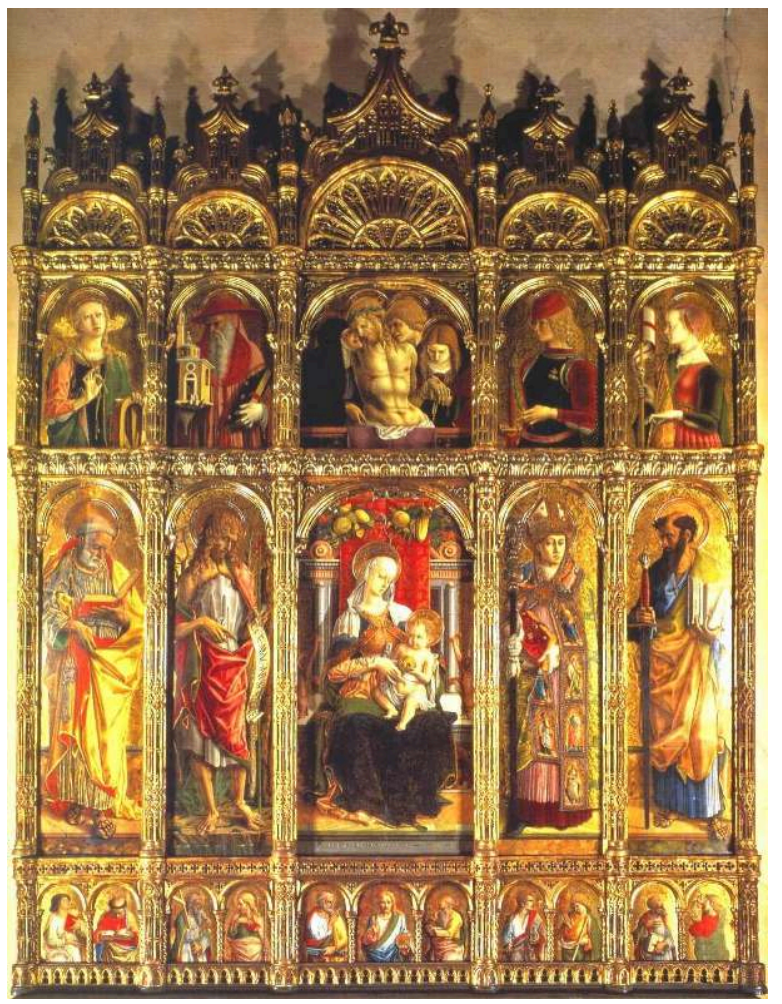

Carlo Crivelli, Polyptyque, 1473, détrempe sur bois, panneau central $136 \times 66 \mathrm{~cm}$, panneaux latéraux $136 \times 39 \mathrm{~cm}$, panneau central supérieur $61 \times 64 \mathrm{~cm}$, panneaux latéraux supérieurs $65 \times 41 \mathrm{~cm}$, prédelle $27 \times 280 \mathrm{~cm}$. Ascoli Piceno, Cattedrale di S. Emidio. DR

Peut-être a-t-il passé quelque temps à Padoue, dans le célèbre atelier de Francesco Squarcione. La Vierge à l'Enfant de Vérone (fig. 3) fait beaucoup penser à la production de Bellini (fig. 4) ou de Mantegna jeunes, ou d'autres disciples de Squarcione, comme Giorgio Schiavone ou Marco Zoppo (fig. 5) : le même goût pour les détails, pour les ruines antiques, pour les curiosités, les guirlandes de fruits, enfin le même dessin très linéaire et nerveux. Bref, on a supposé un séjour de Crivelli dans ce célèbre atelier, qui forma toute l'élite de la peinture, dans les années 1450-60, de l'Italie du Nord-Est. 
Fig. 3

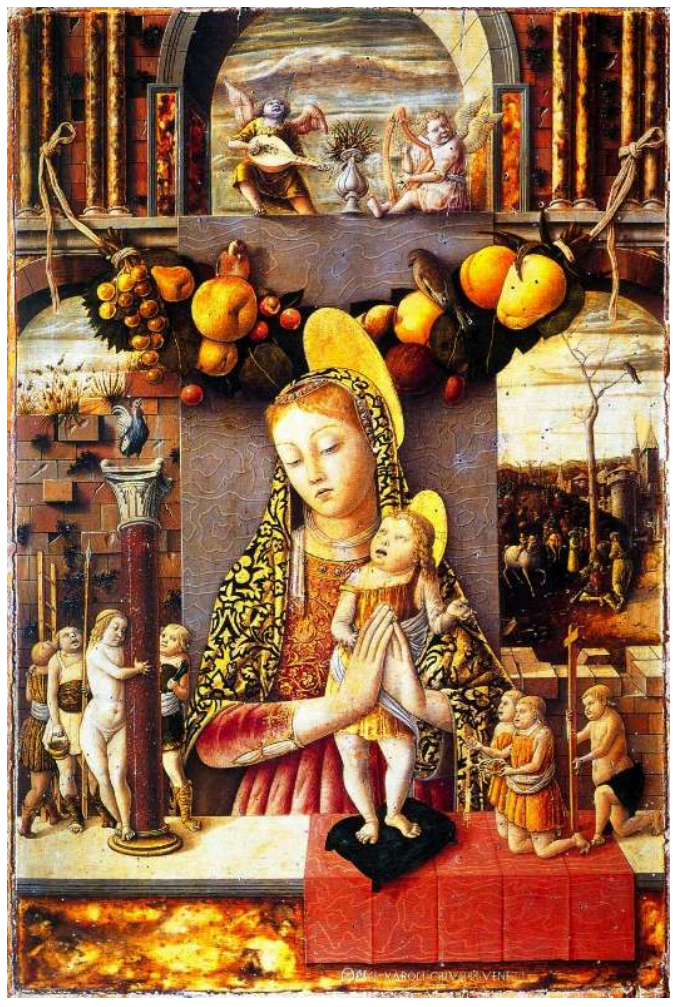

Carlo Crivelli, Vierge à l'Enfant avec les instruments de la Passion, v. 1465-70, détrempe sur bois, 71 x 48 $\mathrm{cm}$. Vérone, Museo di Castelvecchio. DR 
Fig. 4

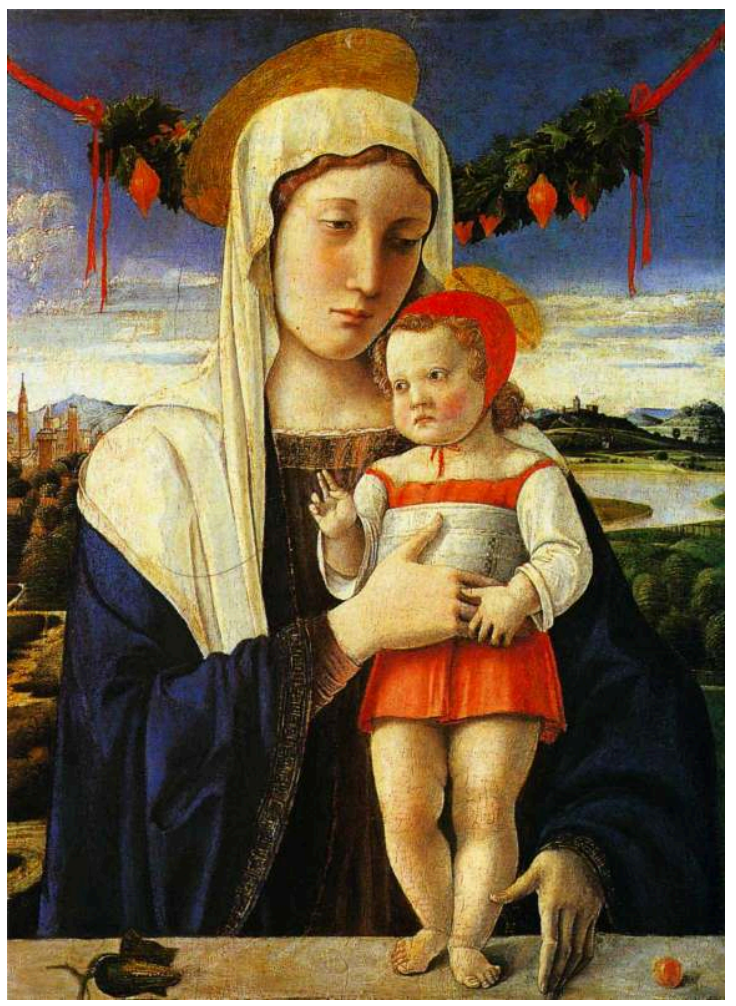

Giovanni Bellini, Vierge à l'Enfant, v. 1470, huile et détrempe sur bois, 54 × 39 cm. New York, Metropolitan Museum of Art. DR 
Fig. 5

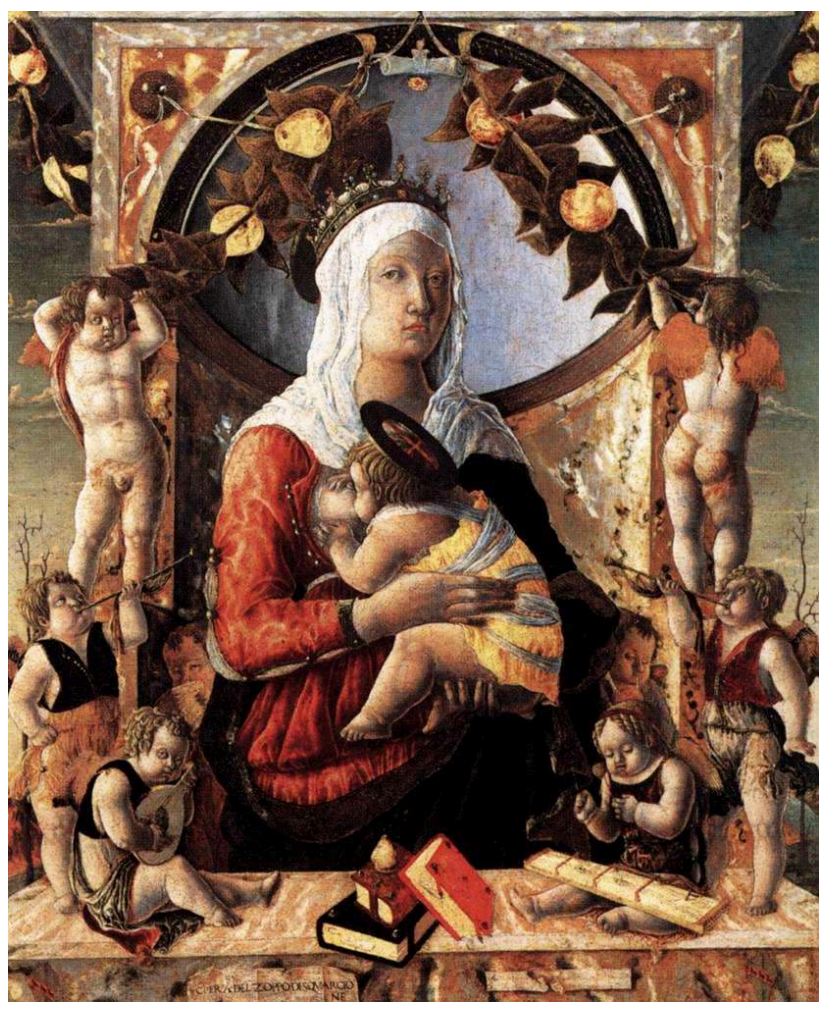

Marco Zoppo, Vierge à l'Enfant avec des anges,1455, détrempe sur toile transférée sur bois, $89 \times 72 \mathrm{~cm}$. Paris, Musée du Louvre. DR

Cependant, si l'on retrouve des caractéristiques communes dans les œuvres de jeunesse de Giovanni Bellini, de Mantegna, de Schiavone, de Zoppo, de Cosmè Tura et de Crivelli, frappe plutôt, outre leur parcours respectif géographiquement éclaté (chacun regagnant sa ville natale pour y faire fructifier sa carrière), l'éclatement stylistique de leur art, quand celui-ci atteint sa maturité. Chacun suit une ligne tout à fait personnelle et caractéristique: quoi de commun entre la douceur et la retenue d'une Madone de Bellini (fig. 6), le délire archéologique et minéral d'un Mantegna (fig. 7), ou l'extravagance ornementale d'un Crivelli (fig. 8) ? 
Fig. 6

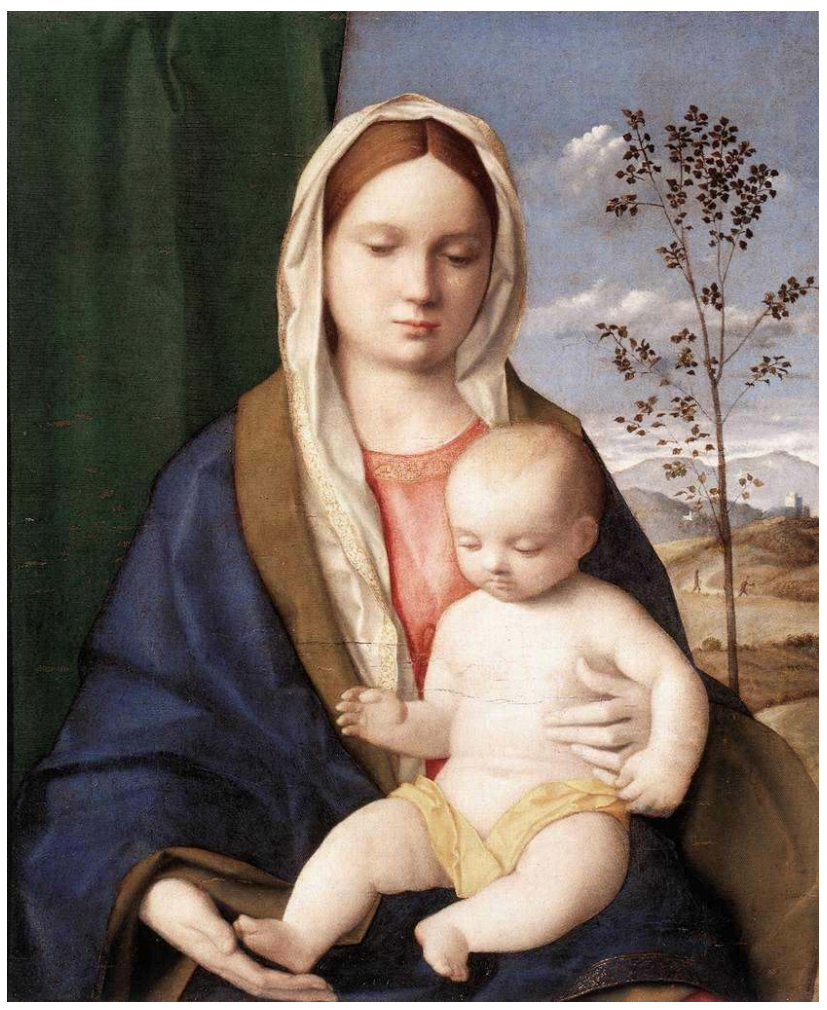

Giovanni Bellini, Vierge à l'Enfant, v. 1510, huile sur bois, 50 x $41 \mathrm{~cm}$. Rome, Galleria Borghese. DR

Fig. 7

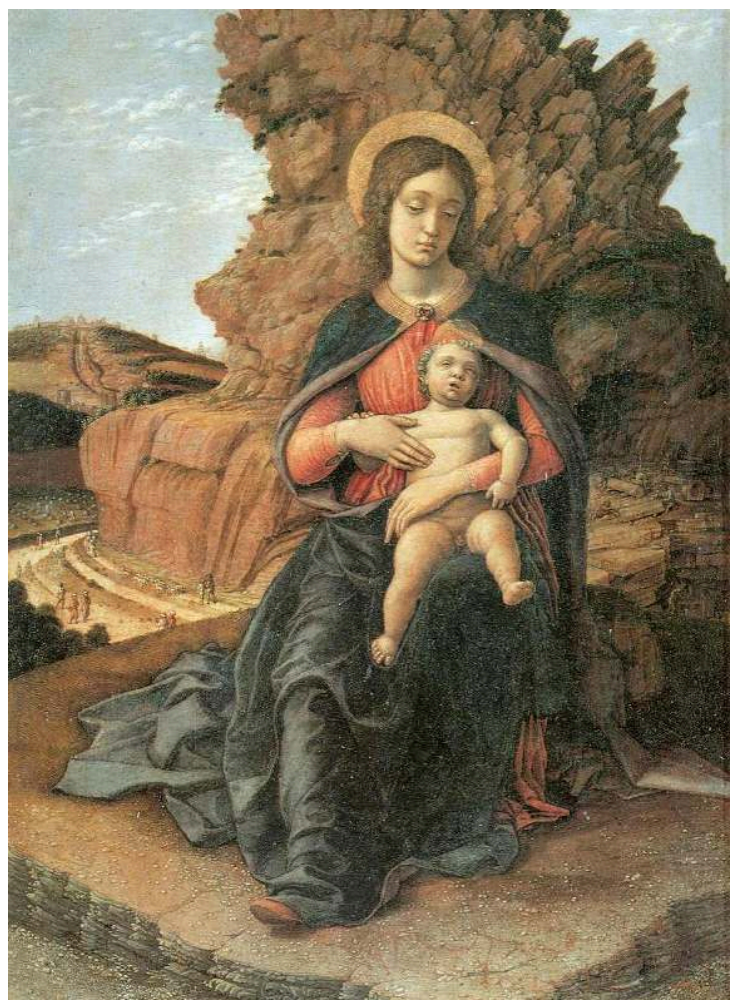

Andrea Mantegna, Vierge à l'Enfant (Madone à la Carrière), v. 1489, détrempe sur bois, 32 × 29,6 cm. Florence, Galleria degli Uffizi. DR 
Vasari affirme que Squarcione était un mauvais peintre, très tôt jaloux de son meilleur élève, Mantegna ${ }^{26}$. Peut-être bien que Squarcione était incapable de transmettre un style propre à ses disciples. Mais il leur a transmis bien autre chose, ce que Vasari était incapable de comprendre: l'envie d'affirmer sa différence, de choisir la voie de l'originalité absolue. Il leur transmit une habitude qui allait de pair avec cette volonté d'affirmation de soi : la signature. Comparativement, les Florentins (Lippi père et fils, Verrocchio, les frères Pollaiolo, Botticelli...) ne signent pas aussi fréquemment leurs tableaux que Bellini, Tura, Crivelli et consors (Mantegna faisant exception). L'absence de signature indique peut-être que ces peintres étaient si connus, que leur style était si reconnaissable qu'il était inutile qu'ils signent leurs œuvres. Il n'empêche: si l'on considère la présence de la signature comme l'indice d'une certaine forme de modernité, c'est moins dans la peinture florentine que dans cette peinture de l'est de l'Italie du Nord qu'il faut la chercher. Les Florentins, à l'instar de Léonard, sont toujours plus rétifs à l'affirmation de soi et de leur style que les disciples de Squarcione.

Fig. 8

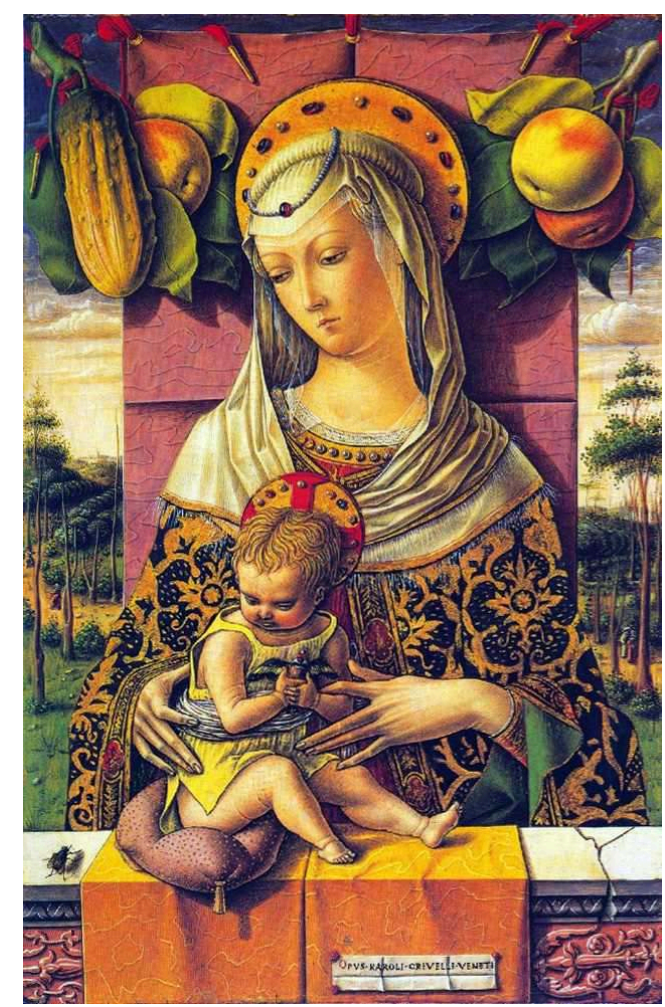

Carlo Crivelli, Vierge à l'Enfant, v. 1480-90, détrempe sur bois, 36,5 x 23,5 cm. New York, Metropolitan Museum of Art. DR

L'affirmation de soi, pour Crivelli, semble d'abord passer par la découverte du style des autres. Il va continuer à voyager et à enrichir sa peinture de sources extérieures. Il traverse l'Adriatique et on le retrouve à Zadar, ou Zara (dans l'actuelle Croatie), quand il s'agissait d'un comptoir vénitien - ceci en 1465. Là-bas, il pouvait voir des peintures très byzantines comme celle de Pietro Jordanic (fig. 9), chaînon manquant entre Crivelli et l'icône ${ }^{27}$. Puis en 1468 on le trouve dans la Marche d'Ancône, où il signe son premier retable. Jusqu'en 1472 il travaille dans la région de Fermo, petite cité importante à l'époque, ouverte sur la mer grâce à son port (Porto S. Giorgio, où Crivelli 
peint un retable en 1471), à deux pas de la frontière avec le Royaume de Naples. Il n'y a pas véritablement de peintre aussi talentueux dans ce territoire, pas de peintre à qui voler des motifs originaux, et Crivelli devient rapidement le peintre de l'élite locale.

Fig. 9

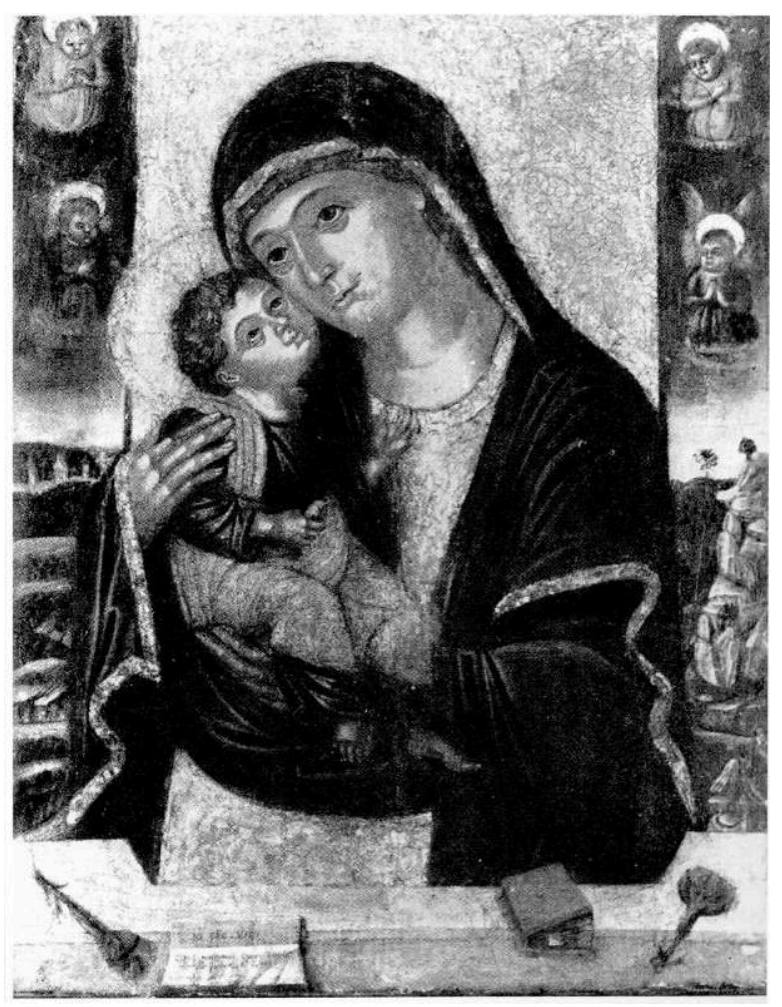

Pietro Jordanic, Vierge à l'Enfant, détrempe sur bois, 51 x $40 \mathrm{~cm}$. Vienne, collection privée. DR

En 1473 il commence à travailler pour la cité rivale d'Ascoli Piceno : plus puissante, plus importante, Ascoli est la deuxième ville de la Marche d'Ancône, après la cité éponyme. Il peint le polyptyque pour le maître-autel de la cathédrale et divers autres retables, jusqu'à l'apothéose, l'Annonciation de 1486 (fig. 10), son chef-d'œuvre, sur lequel les trois armoiries représentées (celle du pape Innocent viII, celle de la Commune et celle de l'évêque) indiquent l'importance officielle de ce tableau ${ }^{28}$. Crivelli en deviendra un habitant reconnu et même un représentant quasiment officiel (en 1490, il rencontre Ferdinand de Capoue qui parle de Crivelli comme un de ses «familiares» et représentant éminent de la ville d'Ascoli ${ }^{29}$ ). 
Fig. 10

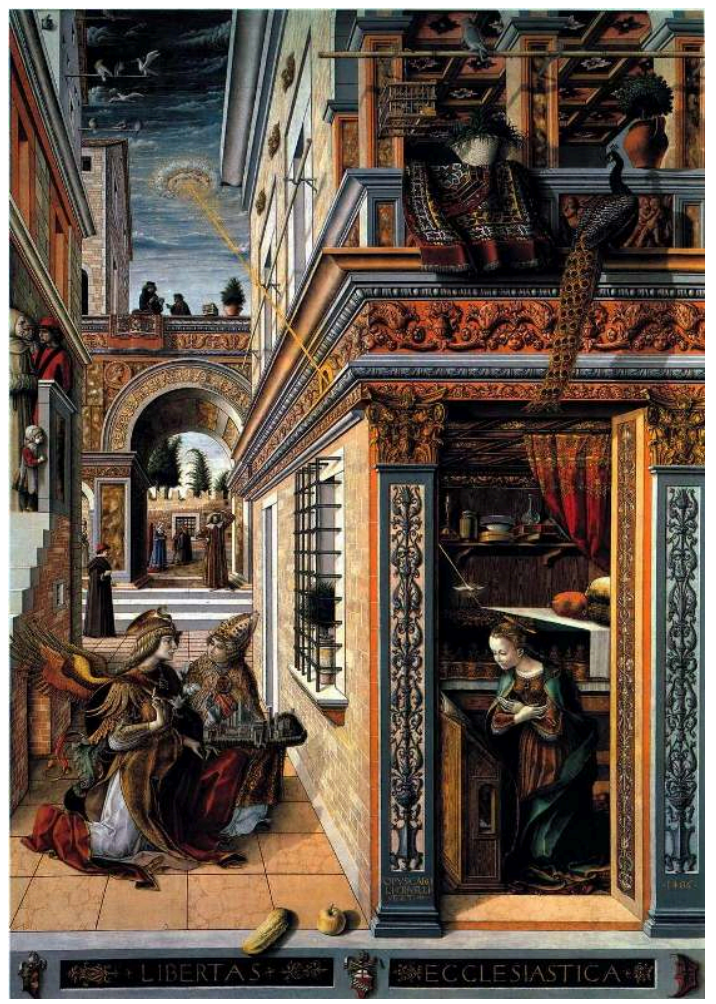

Carlo Crivelli, Annonciation, 1486, détrempe et huile sur toile, 207 x 146,4 cm. Londres, National Gallery. DR

Il est arrivé au sommet. Mais le style de Crivelli ne se fige pas pour autant et lui-même n'arrête pas ses voyages. Il remonte la Marche d'Ancône, rencontrant à Camerino les peintres locaux, dont certains comme Giovanni Boccati et Girolamo di Giovanni connaissent directement la peinture toscane et la peinture ombrienne - Piero della Francesca pour tout dire. L'Annonciation de 1486 (fig. 10), peinte après le premier séjour à Camerino en 1482, témoigne de cette rencontre : elle est inspirée de l'Annonciation de Spermento (fig. 11) ${ }^{30}$, tant par la structure de tableau d'autelunifiéque par le schéma de composition hérité de Benedetto Bonfigli ou de Piero à Arezzo. Crivelli reprendra plus tard l'idée d'une lunette surmontant tout le compartiment central et pourvue d'une Pietà dans son retable pour S. Francesco de Fabriano de 1493 (fig. 12), son dernier travail. Peint à Fabriano, celui-ci, comme les autres œuvres réalisées après 1490 dans cette région limitrophe de l'Ombrie, témoigne aussi d'autres emprunts : c'est à la peinture ombrienne de Perugino (fig. 13) ou de Melozzo da Forlì que font penser ses anges adolescents. 
Fig. 11

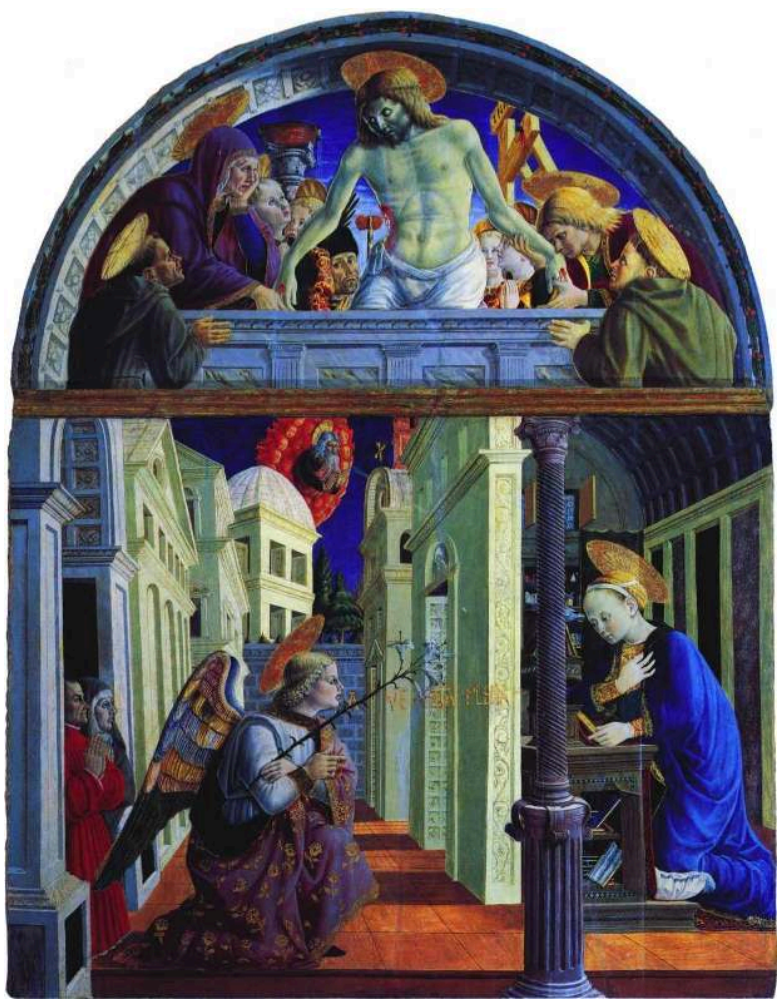

Attribué à Giovanni Angelo Antonio, Annonciation de Spermento,v.1455, détrempe sur bois, $198 \times 152$ $\mathrm{cm}$. Camerino, Pinacoteca et Musei Civici. DR

Cette façon qu'avait Crivelli de récupérer, au fur et à mesure de ses pérégrinations, des motifs, des formes inventés par d'autres peintres, bref cet éclectisme crivellesque a pu gêner un certain nombre d'historiens de l'art habitués à l'idée romantique et moderniste du génie créant ex nihilo son propre monde plastique. On a pu l'accuser d'être " coupable » d'artisanat; c'était un excentrique isolé, perdu dans une voie sans issue, isolé dans une région conservatrice culturellement ${ }^{31}$. Bref on lui reprochait et de s'être coupé d'un véritable foyer de création (Venise) et de s'être replié dans une région marginale et une marginalité plastique sans écho. 
Fig. 12
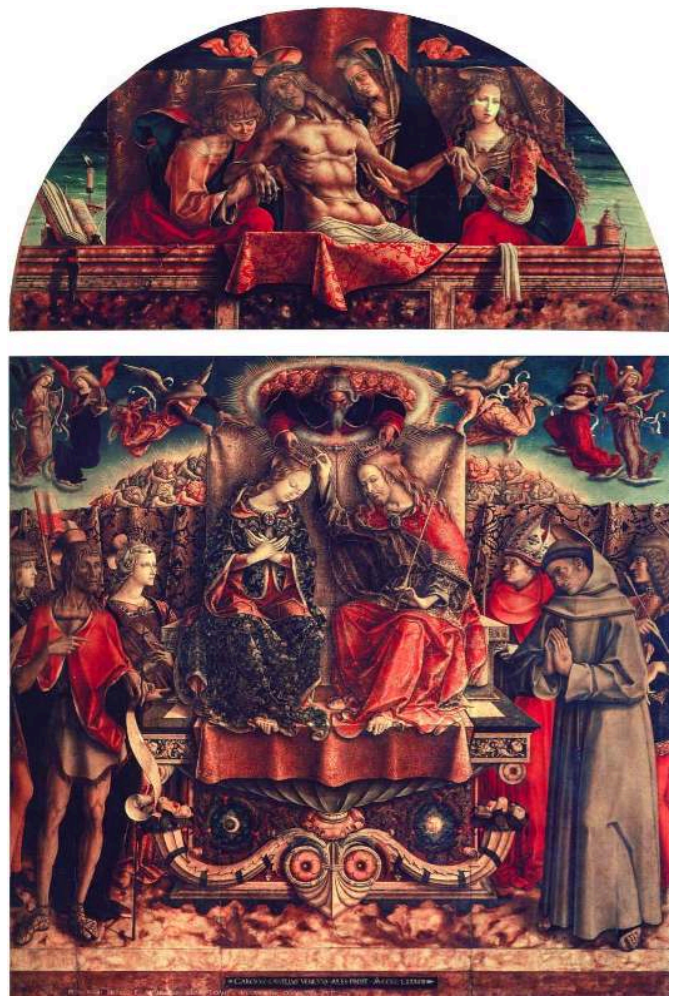

Carlo Crivelli, Couronnement de la Vierge et Pietà, 1493, huile et détrempe sur bois, Couronnement $225 x$ 255 cm, Pietà 131,5 x 244 cm. Milan, Pinacoteca di Brera. DR

Ces reproches, ils proviennent en bonne partie de l'habitude des historiens de l'art à raisonner, comme Vasari, en termes de territoires stylistiques, de généalogies artistiques. Crivelli, nomade adultère, ne pouvait que susciter l'incompréhension. Mais son œuvre et son parcours s'éclaircissent dès qu'on adopte le point de vue de l'alliance et de la déterritorialisation. Crivelli assemble des formes parce qu'il est un «bricoleur». 
Fig. 13

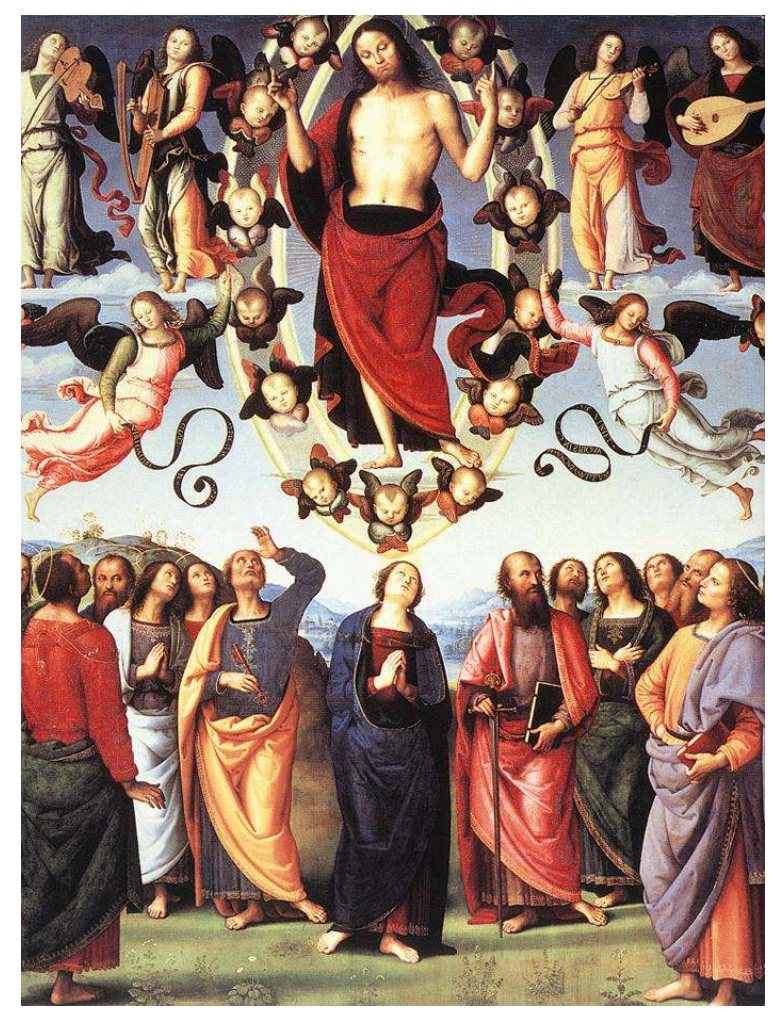

Pietro Perugino, Ascension, 1496-98, huile sur bois, 342 × 263 cm. Lyon, Musée municipal des beauxarts. DR

Or, si le bricolage de Crivelli produit du devenir, c'est que sa peinture ne fait pas qu'assembler des formes : elle monte, de manière aussi complexe, du temps. Son œuvre conjugue en effet des formes gothiques - le polyptyque, le fond d'or, la tonalité religieuse «expressionniste» (fig. 2, 25, 27); des formes byzantines - les Vierge à l'Enfant répétitives (fig. 1, 2, 3, 8), les Imago pietatis (fig. 2, 14, 15) ; des formes renaissantes - la perspective, les trompe-l'œil, la pala (fig. 1, 10, 12, 13, 26, 28). Tout ce qui se faisait à son époque. C'est pourquoi, de même qu'il est difficile de classer Crivelli dans une école à part la sienne, de même il est difficile de le situer dans la chronologie linéaire utilisée habituellement par les historiens de l'art. Crivelli n'a pas la carrière d'un Botticelli, peintre florentin et seulement florentin, formé à l'école Lippi et nourri au lait médicéen. Crivelli récolte ses motifs au cours de ses voyages de nomade, avant de se fixer à Ascoli. C'est comme s'il traversait les époques, ou plutôt, comme s'il les associait, les accolait. 
Fig. 14

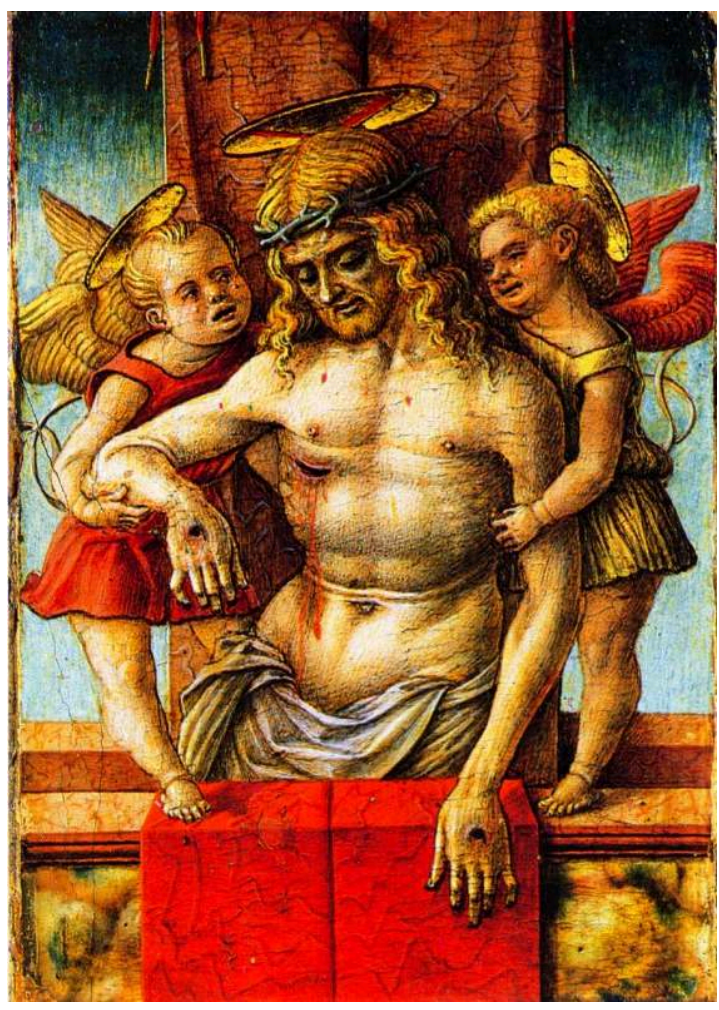

Carlo Crivelli, Imago Pietatis, v. 1470-75, détrempe sur bois, 15 x 12 cm. Paris, Musée du Louvre. DR

Fig. 15

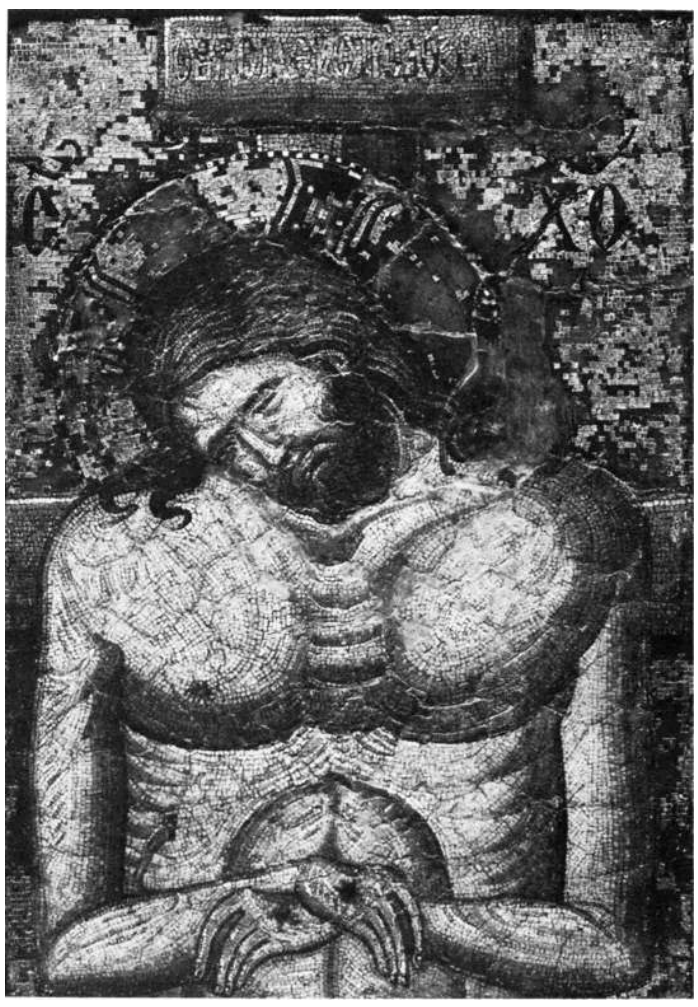

Anonyme byzantin, Imago Pietatis, v. 1300, $13 \times 19 \mathrm{~cm}$. Rome, S. Croce in Gerusalemme. DR 
34

\section{Quattrocento apparaît comme une époque de mélanges et la peinture de Crivelli comme un très bon exemple - pas le seul, ni le plus célèbre ${ }^{32}$ - d'une démarche nomade où l'invention d'un nouveau style est indissociable d'une théorie du montage des temps, de l'alliage des motifs.}

Dans une histoire de l'art fondée sur l'alliance et non plus sur la filiation, le

Envisagée de la sorte, sa peinture fournit une image directe de son époque: leur « impureté » se répond. Une époque où se côtoient des temporalités hétérogènes, des modes de pensée différents (païen, chrétien religieux ou laïc), dans un tout singulier et qui ne cesse d'évoluer. Warburg en son temps et Didi-Huberman à sa suite l'ont bien vu : ne serait-ce que dans un buste de Donatello se superposent l'imago républicaine, le portrait sculpté impérial, le chef-reliquaire et le masque mortuaire contemporain ; une superposition que Warburg nommait «survivance ${ }^{33}$. Dans les fresques de Schifanoia, l'esprit courtois, le savoir arabe médiéval, la mythologie grecque et le style propre aux peintres ferrarais font un palimpseste visuel remarquable. Le Quattrocento multiplie les exemples de ce genre. Ce n'est pas une vue de l'esprit récente : Baxandall avait remarqué que les humanistes eux-mêmes avaient du mal à établir une chronologie aussi linéaire pour le $\mathrm{XV}^{\mathrm{e}}$ siècle qu'ils ne l'avaient fait pour le $\mathrm{XIV}^{\mathrm{e}}$, où il suffisait de dérouler la succession des générations de peintres après Giotto, qui s'éloignant de plus en plus de leur modèle, s'éloignent du même coup de l'art véritable ${ }^{34}$. Mais le $\mathrm{xV}^{\mathrm{e}}$ siècle est trop divers, trop multiple. Il faudra toute la partialité anti-vénitienne et proflorentine de Vasari pour réussir, au prix de grosses injustices et de gros oublis (Crivelli !) à «toscano-centrer » et à linéariser l'histoire de l'art du Quattrocento, qui est censé préparer la « bella maniera » de son siècle.

\section{La tribu Crivelli}

Mais reste que Crivelli lui-même a fait l'objet d'une imitation de sa peinture par tout ce que la Marche d'Ancône comptait de peintres, depuis son propre frère Vittore jusqu'au plus obscur et au plus médiocre barbouilleur de paese marchisan. Ses épigones semblent n'avoir pas compris le principe mosaïque qui guidait l'art du maître, et avoir pris son style d'un seul tenant. Tout se passe comme si Crivelli était devenu le chef d'une école de peinture régionale, comme si son style s'était finalement territorialisé, comme s'il était rentré dans le rang du schéma généalogique. Et en effet, on peut observer que, à partir de son installation à Ascoli vers 1473, Crivelli entre dans une phase de relative fixation. Son style s'est désormais stabilisé : très luxueux, très détaillé, il ne lésine ni sur les brocarts d'or ni sur les fausses pierres précieuses, il affiche une virtuosité incroyable dans son traitement des difficultés de l'art (les raccourcis, la minutie des objets, le rendu des matériaux). Et surtout, il a trouvé sa marque de fabrique, une signature ornementale : le concombre, qui fait son apparition dans le retable du Duomo d'Ascoli (fig. 2)et ne quitte quasiment plus sa peinture jusqu'à la fin (fig. 1, 8, 10, 12, 25, 30). Ce concombre dont les historiens de l'art cherchent coûte que coûte la signification symbolique ${ }^{35}$ mais aussi en vain : il faudrait plutôt le voir comme un objet plastique, tombé des festons de fruits antiquisants dont les élèves de Squarcione étaient si friands (fig. 16), et qui prend son indépendance visuelle comme Crivelli son indépendance artistique.

Images Re-vues, 9 | 2011 
Fig. 16

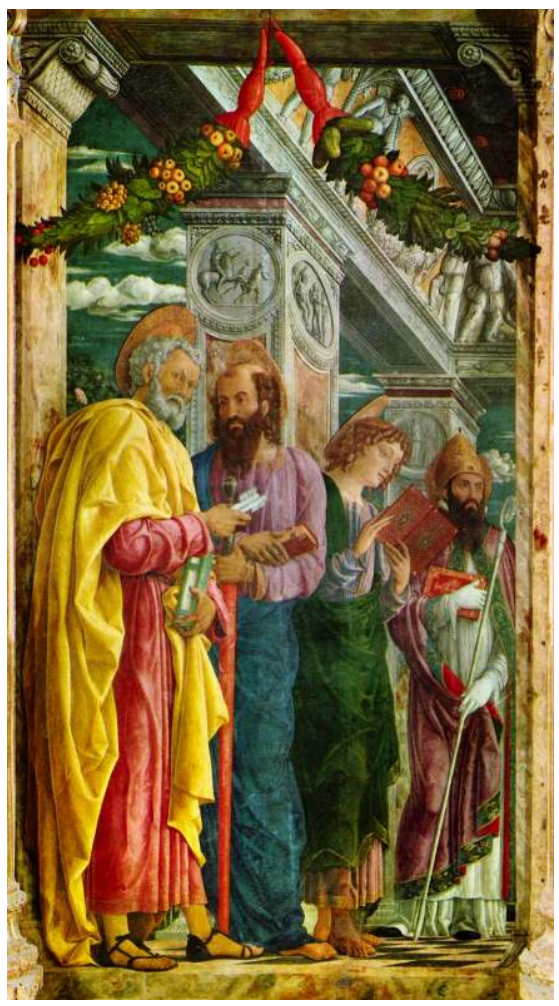

Andrea Mantegna, Triptyque de S. Zeno (panneau gauche), 1459, détrempe sur bois, $134 \times 213 \mathrm{~cm}$. Vérone, Basilica di S. Zeno Maggiore. DR

37 L'installation à Ascoli est une période de fixation aussi parce qu'il attire à lui des disciples qui vont suivre sa voie: Pietro Alemanno qui s'est lui aussi basé à Ascoli, et son propre frère, Vittore, attesté dans la Marche d'Ancône à partir de 1479 et qui suit de près ses traces. Même si la démarche personnelle de Crivelli le pousse au mouvement, on l'attache malgré tout au territoire, à la cité d'Ascoli. 
Fig. 17

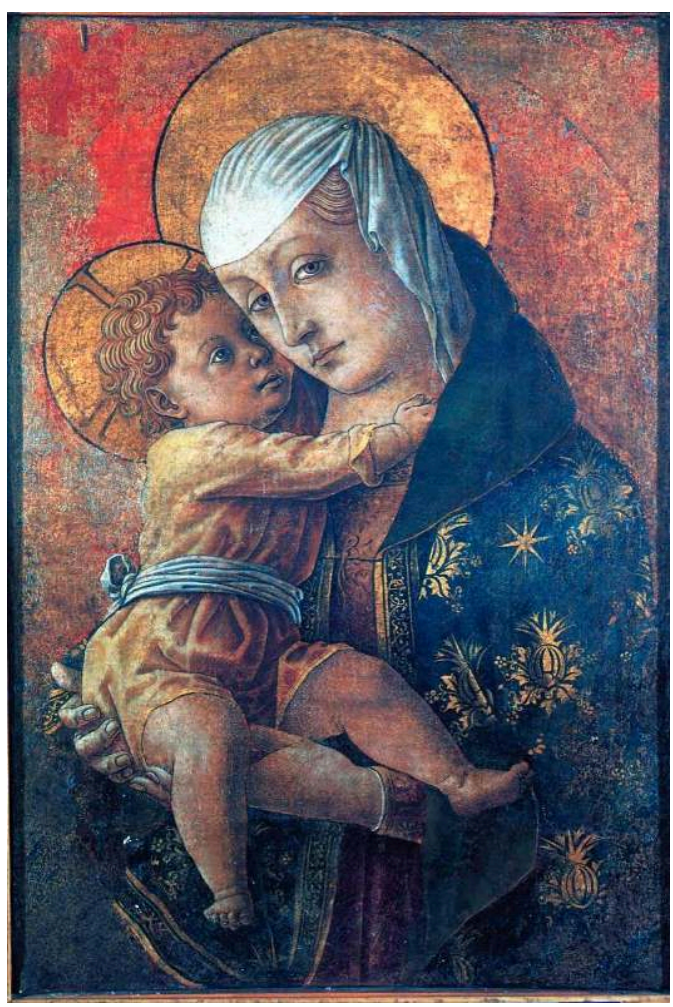

Carlo Crivelli, Vierge à l'Enfant, 1470, détrempe sur toile, 59 × 40 cm. Macerata, Civica Pinacoteca. DR

Fig. 18

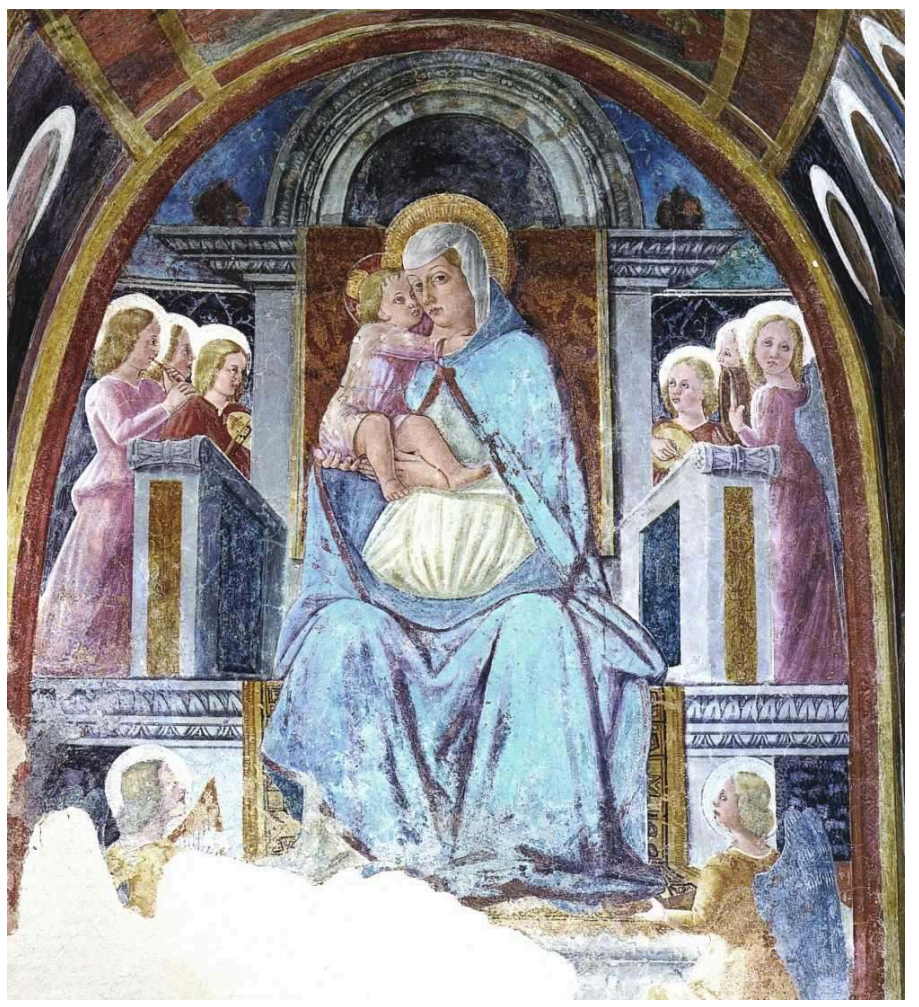

Attribué à Giovanni Angelo d'Antonio, Vierge à l'Enfant et anges, v. 1470-75, fresque détachée, 142 × 164 $\mathrm{cm}$. Camerino, Pinacoteca e Musei Civici. DR 
La ressemblance stylistique entre la peinture de Crivelli et celle de ses suiveurs est frappante. Parfois il s'agit d'une copie pure et simple, comme à Camerino, où la Vierge à l'Enfant de Crivelli à Macerata (fig. 17) est reproduite traits pour traits dans une fresque attribuée à Giovanni Angelo d'Antonio (fig. 18) ${ }^{36}$. Parfois, comme chez Pietro Alemanno, qui signe l'un de ses retables "Opus Petri Alamanni discipuli Caroli Crivelli » ${ }^{37}$, il s'agit d'une ressemblance plus générique, qui passe par les décorations précieuses des vêtements des saints, des draps d'honneur et des fonds d'or, par les visages anguleux et grimaçants, les corps expressionnistes, l'usage des pastiglie a rilievo et des fausses pierres précieuses pour les couronnes, auréoles et autres objets de pouvoir, et parfois le fameux concombre, marque de fabrique de Crivelli (fig. 19, 20, 21).

Fig. 19

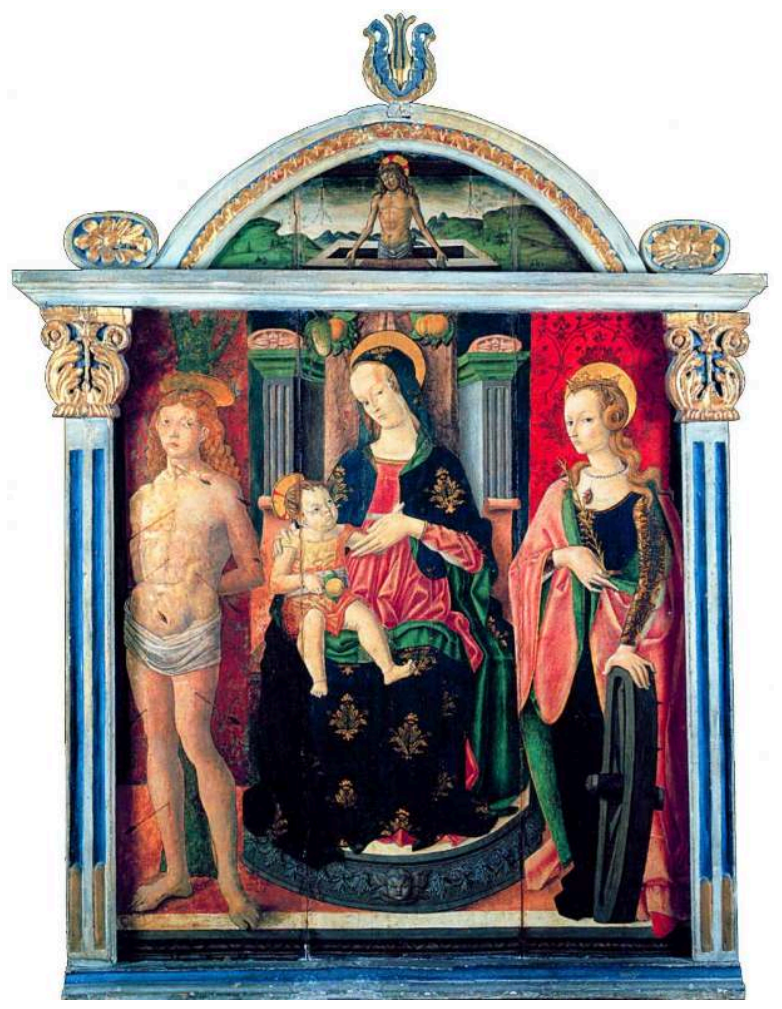

Pietro Alemanno, Vierge à l'Enfant entre saint Sébastien et sainte Catherine, v. 1485-95, détrempe sur bois, 197 x $160 \mathrm{~cm}$. Ascoli Piceno, Pinacoteca Civica. DR 
Fig. 20
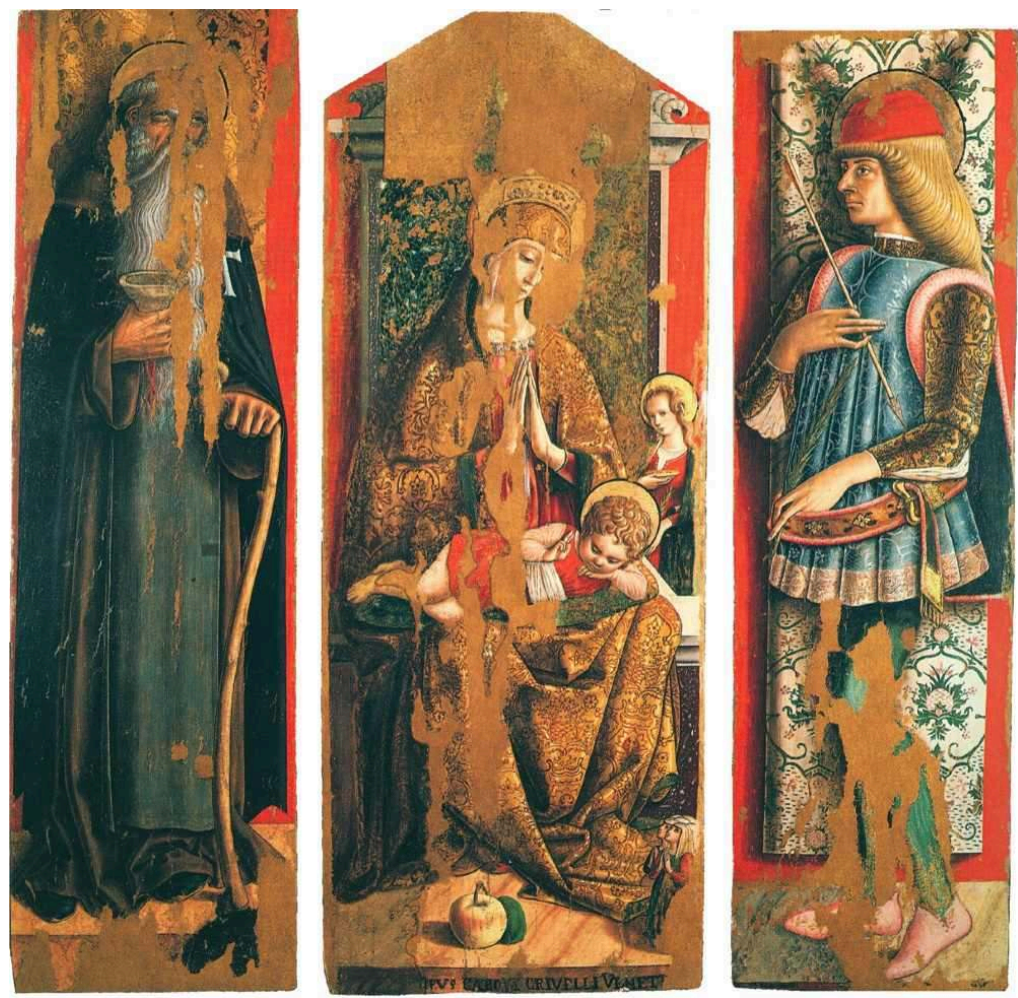

Carlo Crivelli, Vierge à l'Enfant entre saint Antoine abbé et saint Sébastien, v. 1476, détrempe sur bois, panneau central 132 × $50 \mathrm{~cm}$, panneaux latéraux 132 × $39 \mathrm{~cm}$. Ascoli Piceno, Pinacoteca Civica. DR 
Fig. 21
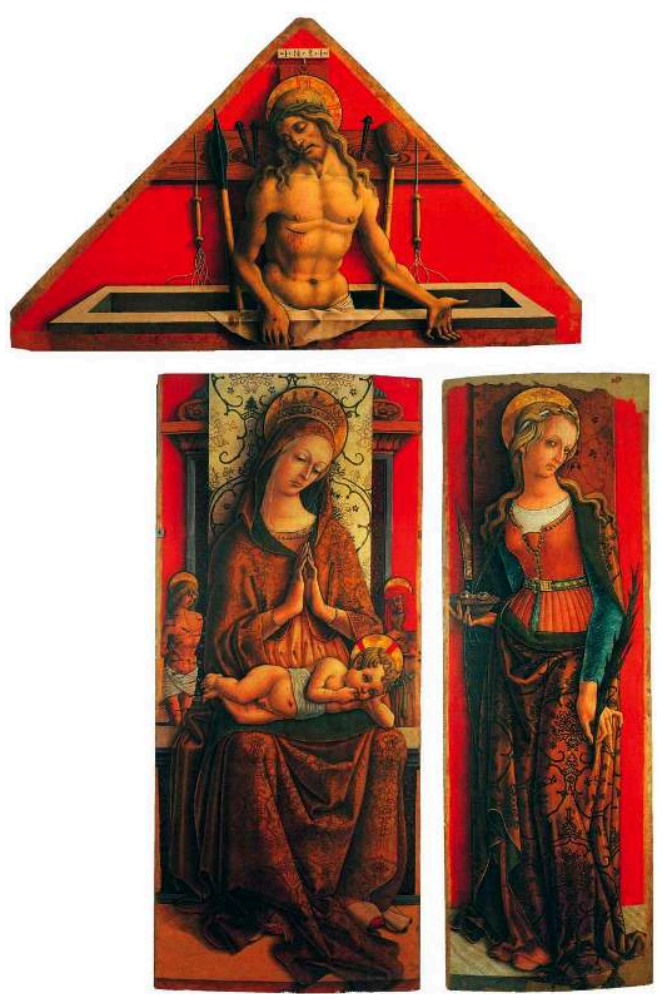

Pietro Alemanno, Vierge à l'Enfant entre saint Sébastien et saint Côme, Sainte Lucie et Imago Pietatis, v. 1475-80, détrempe sur bois, panneau central $117 \times 47 \mathrm{~cm}$, panneau latéral $122 \times 39 \mathrm{~cm}$, lunette $57 \times$ $100 \mathrm{~cm}$. Montefortino, Pinacoteca Civica. DR

Qu'il s'agisse de traits stylistiques formant un agencement cohérent aux yeux des peintres marchisans est montré par l'exemple d'un autre peintre, Lorenzo d'Alessandro de San Severino. Comme une éponge celui-ci a absorbé au cours de sa carrière des styles très différents, de Crivelli à Signorelli. Son tableau crivellesque, le Mariage mystique de sainte Catherine (fig. 22), est l'un de ses meilleurs; on y retrouve les brocarts dorés, les traits anguleux, le concombre - qui disparaissent ensemble quand Lorenzo d'Alessandro passe à un autre style. 
Fig. 22

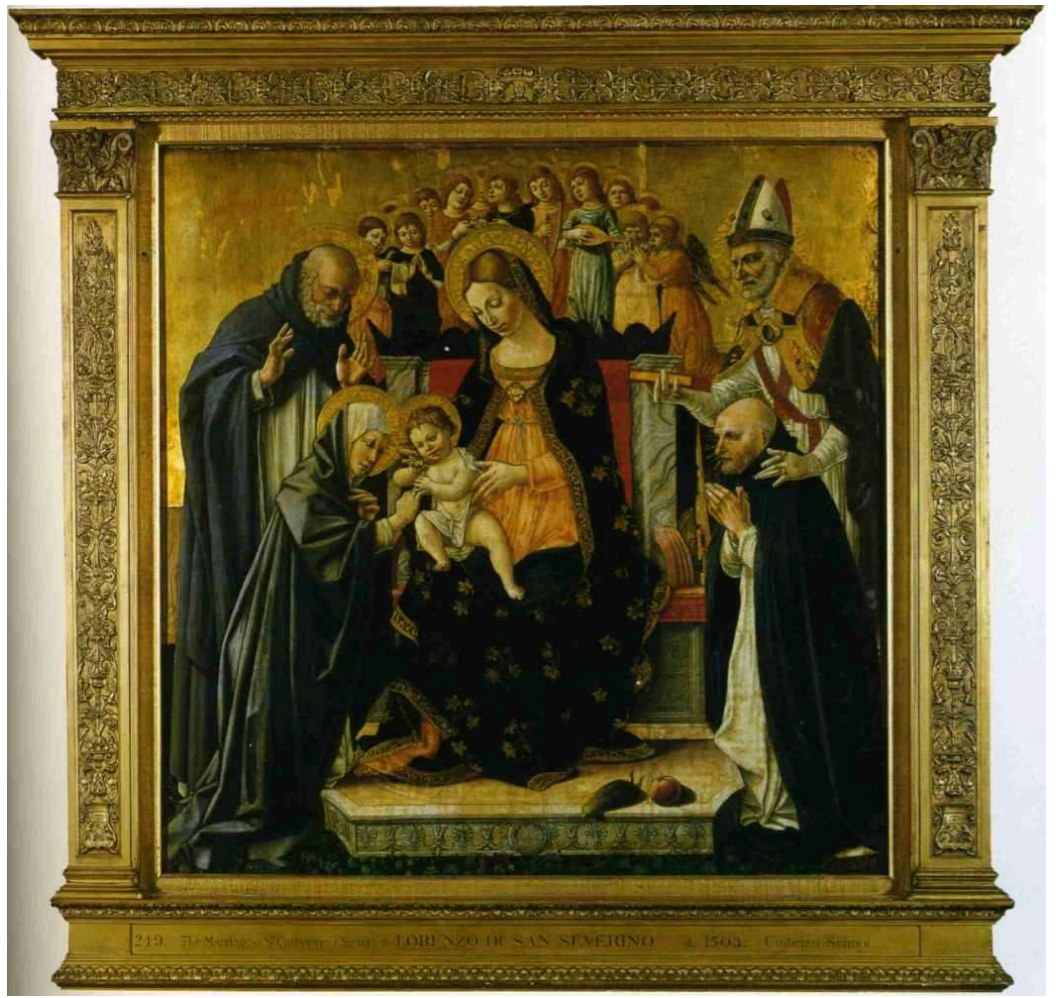

Lorenzo d'Alessandro, Mariage mystique de sainte Catherine, v. 1480-1500, détrempe et huile sur bois, $144,8 \times 145,4$ cm. Londres, National Gallery. DR

Mais le cas le plus évidemment frappant de cette ressemblance stylistique est celui du propre frère de Crivelli, Vittore. La ressemblance est si criante que pendant longtemps les historiens de l'art se sont battus pour attribuer tel retable non signé à l'un ou à l'autre. On pense même qu'ils ont collaboré au moins une fois, dans le grand polyptyque de Monte S. Martino (fig. 23), car les panneaux de ce retable, de plus ou moins bonne qualité, ont été attribué tantôt au frère ainé, tantôt au $\operatorname{cadet}^{38}$. 
Fig. 23

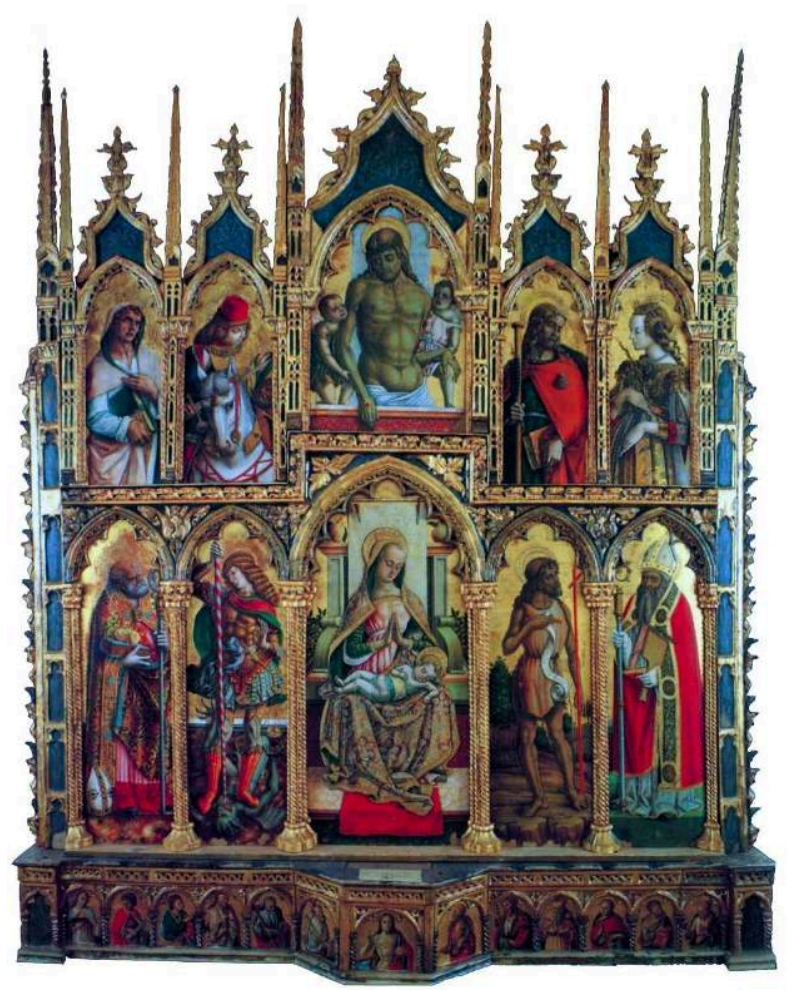

Carlo et Vittore Crivelli, Polyptyque, v. 1475-85, détrempe sur bois, 285 × 227 cm. Monte San Martino, San Martino. DR

Évidemment ressemblance ne signifie pas similitude et on peut observer des différences entre le style du maître et celui de ses suiveurs. Pietro Alemanno a le trait plus épais et aime les aplats de couleur; Vittore Crivelli fait les visages de ses personnages plus tristes et développe des iconographies qui lui sont propres; et il ajoute au concombre de son frère un œillet rouge plus personnel (fig. 24). Mais le fait est qu'on assiste à un phénomène d'assimilation stylistique très net, très circonscrit. Or on pourrait ramener ce phénomène au modèle de la filiation: la ressemblance est le produit de la génération. Crivelli insufflerait la semence stylistique à ses «enfants » de peinture. On pourrait le comparer, toutes proportions gardées, à ce que décrit Vasari à propos de Giotto et des giottesques : transmission stylistique du maître aux élèves dans le cadre de l'atelier, du territoire, de l'aria florentine. On pourrait conclure qu'au nomadisme de la période de formation, où prédominance l'alliance, succède la sédentarisation de la période de maturité, où prédomine la filiation. 


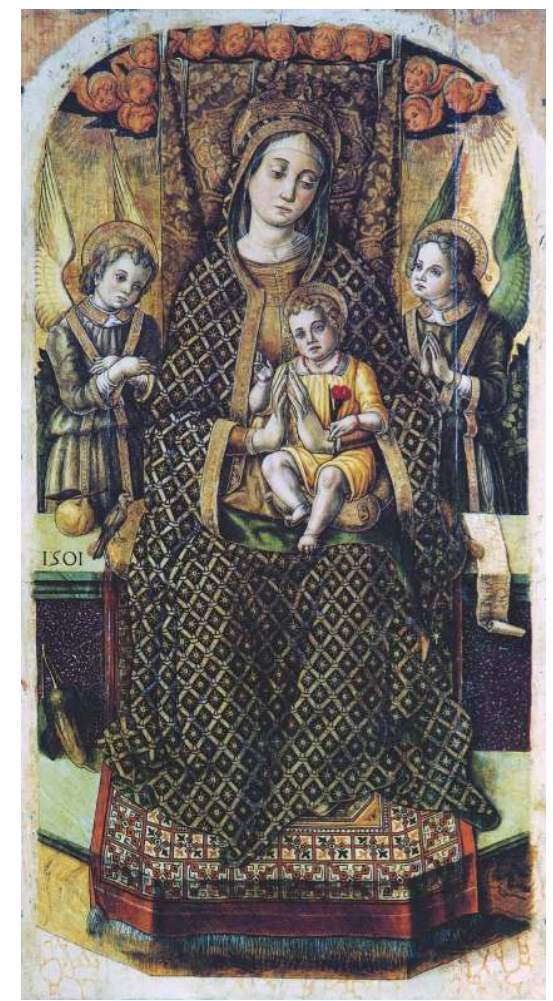

Vittore Crivelli, Vierge à l'Enfant avec anges, 1501, détrempe sur bois, 138 × 75 cm. Avignon, Petit Palais. DR

Pourtant, on fera ici l'hypothèse que le crivellisme (diffusion du style de Crivelli à d'autres peintres du même territoire) ne relève pas non plus d'une transmission par filiation, mais bien plutôt par contagion, autre forme de l'alliance : il s'agit toujours d'un accroissement par le dehors. Autrement dit, compte moins ici la ressemblance (dégradée) entre le style des crivellesques et celui de Crivelli que le processus d'imitation par lequel les premiers cherchent à se hisser au niveau du second. Ou encore: à l'idée d'une transmission d'un principe stylistique du haut vers le bas, analogue à la transmission des caractères spécifiques du père au fils selon le modèle biologique aristotélicien de la filiation, il faut préférer l'idée d'une conformation du bas vers le haut, analogue à l'imitation valorisée et pratiquée dans les milieux monastiques, sur le modèle des saints confesseurs.

$$
43
$$

"Qui m'a vu, a vu le Père ", affirme Jésus dans l'évangile de Jean $(15,4)$. Dans les interprétations de ce passage par les Pères de l'Église, ressemblance et identité se confondent : le Christ est Dieu parce qu'il lui ressemble absolument ${ }^{39}$. En totale rupture avec le platonisme qui imposait l'idée d'une dégradation nécessaire de l'image envers son modèle, la théologie chrétienne affirme la possibilité paradoxale d'une image qui soit à la fois différente et identique à son modèle : le Fils et le Père sont deux personnes mais ils ont la même nature (ils sont Dieu). On retrouve alors le principe généalogique de ressemblance par filiation, poussé à son extrême limite.

Il n'est en tout cas pas applicable à l'être humain, même saint. Comme le dit excellemment Alain Boureau, «La vie chrétienne enchaîne donc des séries de copies du récit dont la vie de Jésus est l'original. Mais l'imperfection nécessaire de chaque copie 
empêche la duplication de l'événement, que prépare pourtant son évocation sans fin. $»^{40}$. Imperfection parce que, pour les Pères, notamment saint Augustin, depuis la Chute, l'homme (à plus forte raison la femme) ne pouvait plus dire qu'il était « à l'image et à la ressemblance de Dieu ». Pour reprendre l'évêque d'Hippone, l'homme erre sur terre «dans la région de la dissemblance »"1. Le moi chrétien est clivé entre ce qu'il est (une image ratée) et le modèle qu'il cherche à être (une image conforme). Olivier Boulnois le dit en une formule lapidaire: "Soi-même comme une image, telle pourrait être la définition de l'anthropologie médiévale. ${ }^{42}$ » Au mieux, il ne pourra pas être pour lui-même, mais devenir une image de Dieu aussi parfaite que le Christ. Aussi les professionnels de la foi - les saints, puis les moines - n'auront-ils pour but existentiel que cette imitation. L'ascèse du moine consiste moins à se "connaître soi-même ", comme le voulait Socrate, qu'à connaître sa faiblesse, à se reconnaître comme image imparfaite de Dieu, du Christ, et à chercher à lui ressembler.

Cette logique, observable dans les Vies des Pères, les martyrs et les confesseurs des débuts du christianisme, se trouve renforcée vers le XIII ${ }^{\mathrm{e}}$ siècle en Europe occidentale. À partir de cette époque en effet, au moment où apparaissent les ordres mendiants, c'està-dire au moment où la vie urbaine et la voie laïque commencent à dominer l'ancienne société féodale et que les monastères bénédictins, implantées au beau milieu des campagnes, sont concurrencés par les couvents franciscains et dominicains, fondés dans les centres-villes, on observe globalement un changement majeur dans les hagiographies: des saints imitateurs du Christ, martyres admirables et faiseurs de miracles, on passe à des saints imitables, modèles exemplaires de comportement pour laïcs dévots ${ }^{43}$. Le fidèle laïc veut dorénavant être intégré à la vie religieuse et aborder de manière sensible le divin, le mettre à sa portée intellectuelle et matérielle ${ }^{44}$. Les saints deviennent des modèles parce qu'ils imitent eux-mêmes le Modèle. La Vie du saint est généralement une vaste entreprise typologique de concordance avec celle de Jésus; les Évangiles fournissent un certain nombre de topoi hagiographiques que le saint doit parcourir, les uns après les autres, pour gagner sa place au Paradis.

Ainsi, à en croire Alain Boureau, La légende dorée du dominicain Jacques de Voragine serait construite de façon à établir une série de types de sainteté limitée que les saints répèteraient, les uns et les autres, avec des variations dues à leur histoire particulière ; répétition continue particulièrement remarquable quand il aborde les saints contemporains, comme le fondateur de son ordre, Dominique, dont beaucoup d'épisodes de sa vie seraient calqués sur celle d'Antoine Abbé, l'ermite légendaire ${ }^{45}$. Mais l'exemple le plus évident d'une vie sainte consacrée tout entière à l'imitation de Jésus est constitué par saint François. Ses hagiographes successifs n'auront de cesse d'affiner la ressemblance ${ }^{46}$ : épisode de la dénudation et du don du manteau à un pauvre (sur le modèle de saint Martin), vie évangélique avec les premiers compagnons, invention de la crèche à Greccio (ou comment rejouer la Nativité). Mais surtout, la vie de François est encadrée par deux face-à-face avec l'image de Jésus : le Crucifix de San Damiano, qui lui parle alors que François cherche encore sa vocation; et le Séraphin du Mont Averne, qui imprime les stigmates de la Passion sur le corps de François, enfin parvenu, à la fin de son existence, à une ressemblance parfaite ${ }^{47}$. Toute la vie du saint d'Assise (et l'évolution des différentes rédactions de sa vie) peut donc être lue comme un progrès dans l'imitation. Par la suite, c'est saint François lui-même qui fera l'objet d'imitateurs, au sein de son ordre. 
Ainsi, il est facile de remarquer comment au $\mathrm{xv}^{\mathrm{e}}$ siècle, à un moment où dans le Nord de l'Europe se répand le best-seller de Thomas a Kempis, l'Imitation de Jésus ${ }^{48}$, le mouvement de l'observance franciscaine a pensé sa propre histoire comme une imitation des origines du franciscanisme (elles-mêmes imitation des origines du christianisme $)^{49}$. Ce mouvement, fondé au milieu du siècle précédent par Paoluccio Trinci ${ }^{50}$, réagissait contre les franciscains « conventuels » à qui ils reprochaient leurs compromis avec le monde, leur trop relatif respect de la vertu de Pauvreté et leur plus grand souci des débats théologiques que de l'âme des paroissiens ${ }^{51}$. L'Observance, qui veut retrouver l'esprit des premiers franciscains, respecter le testament de saint François, connaît, grâce au charisme de saint Bernardin de Sienne (mort en 1444, canonisé en $1450^{52}$ ) et de ses disciples un succès rapide auprès des laïcs mais ne réussira pas à prendre le pouvoir au sein de l'ordre franciscain (le seul pape franciscain du $\mathrm{Xv}^{\mathrm{e}}$ siècle, Sixte Iv, était un Conventuel). L'entreprise hagiographique des Observants, autour de la canonisation de saint Bernardin, des procès de béatification de ses disciples et des recueils de vies des frères les plus remarquables de l'Ordre - comme les Fioretti ou la Franceschina - aura eu pour but évident d'aider cette légitimation difficile de leur mouvement.

Les hagiographies de Bernardin n'ont de cesse de l'assimiler à saint François ${ }^{53}$. Les disciples de saint Bernardin suivront la même voie, avec leur propre maître, à l'instar de Jacques de la Marche, né et actif dans la région de Crivelli. Développons un peu cet exemple. Les relations entre les deux franciscains sont riches : Jacques de la Marche accompagne plusieurs fois Bernardin dans ses prédications itinérantes; il le défend pendant les procès de 1427 à propos du culte du Nom de Jésus ${ }^{54}$; il prononce son éloge lors de la cérémonie de canonisation, et plusieurs sermons sur lui ensuite ${ }^{55}$. Il est donc admis que Jacques de la Marche est un "nouveau Bernardin $»^{56}$ et, comme lui, une image de François (et donc du Christ). Ainsi, selon son hagiographe, fra Venanzio da Fabriano, fra Giacomo « fut toujours pauvre et méprisable dans la façon de se vêtir; dans la nourriture et dans chaque chose qu'il utilisait, brillait la pauvreté $»^{57}$. Avant de mourir il demandait qu'on le déshabille entièrement, pour qu'il soit enterré nu, " comme mourut Jésus-Christ "

50 C'est donc à une véritable "parenté hagiographique ", pour reprendre l'heureuse expression de Chloé Maillet ${ }^{59}$, qu'on a ici affaire. Elle est indissociable de la structure des ordres monastiques et de la vie au couvent : les «frères " sont tous égaux entre eux et devant Dieu ; mais, dans le même temps, ils élisent un abbé ou un gardien qui devient leur "père " et à qui ils doivent la plus parfaite obéissance (qui est l'une des trois vertus fondamentales de l'ordre franciscain). La construction hagiographique des ordres monastiques ajoute à ceci une dimension dynamique et historique : ce sont les meilleurs moines ou frères qui deviennent naturellement les fondateurs, les abbés et les gardiens des couvents et des monastères (puis, dans certains cas, les saints de l'ordre). Le "père " monastique n'est pas seulement un primus inter pares, il est un modèle à suivre, une image vivante de Jésus, du Bon Pasteur, auquel les moines sont incités à se conformer. La "famille» hagiographique ne fonctionne donc pas comme une famille biologique, où riment descendance et ressemblance, puisque entre le saint et ses disciples, le gardien d'un couvent et ses confrères, règne une dynamique ascendante d'imitation. nomme une "sainte tribu $»^{60}$ : entre le saint et ses compagnons circule un "air de 
ressemblance » qui est le signe de leur élection divine ; la lignée du saint est conçue à l'image des lignées aristocratiques, fondées sur des origines mythiques et sur des valeurs militaires (les « soldats du Christ») ; et elle s'inscrit dans un territoire (le lieu d'activité du saint, où généralement, on vénère ensuite ses reliques). En fait cette analogie avec la noblesse est trompeuse: elle présuppose encore le modèle généalogique de la filiation; et elle sert surtout de légitimation historique des ordres monastiques à un moment où la noblesse elle-même commence à être pensée en termes de transmission héréditaire ${ }^{61}$.

$$
52 *
$$

La ressemblance, dans la théorie chrétienne, n'est donc jamais donnée : elle est à conquérir. C'est un travail sur soi : une conformation. Et si la ressemblance est un travail, si l'imitation (de Jésus) est une quête existentielle, la plus noble dans l'esprit du christianisme, alors les spécialistes de l'imitation, les fabricants d'image, sont peutêtre, comme les moines, des guides dans cette démarche. Le culte des images est indissociable du culte des saints, quasiment dès les origines du christianisme. Dans les débats byzantins entre iconophobes et iconodules, la formule de Basile de Césarée justifiant le culte des images sans pour autant l'assimiler à de l'idolâtrie s'est révélée la plus efficace et la plus durable (c'est la plus reprise jusqu'au Concile de Trente): «l'hommage rendu à l'image remonte au prototype ». Autrement dit, les chrétiens ne vénéraient pas les images matérielles en tant qu'objets, comme les idolâtres, mais en tant que représentations fidèles des personnages sacrés; les images n'étaient que des intermédiaires destinées à les aider dans leurs prières. Le "prototype » que les images représentaient, c'était donc le Jésus, la Vierge, les saints historiques; mais pour les peintres d'icônes, le prototype signifiait la première image, celle qui avait été produite en direct devant le modèle, et qu'ils cherchaient à copier pour rester au plus près de celui-ci. Ce "conformisme » des peintres d'icônes se manifeste surtout après la crise iconoclaste : Belting l'analyse comme une prise de contrôle, par le pouvoir impérial, de l'image des saints, et donc de leur culte, et une centralisation institutionnelle des modes valables de représentation ${ }^{62}$.

En Occident, on le sait, une telle centralisation n'a pas lieu avant la Contre-Réforme ; en conséquence de quoi la représentation des personnages sacrés parait beaucoup plus diverse et libre pendant le Moyen Âge. Cependant, c'est dans la construction hagiographique elle-même que se manifeste un certain conformisme - surtout quand le saint appartient à un ordre monastique. Quand de nouveaux saints sont canonisés, il apparaît tout naturel que leurs images matérielles portent autant le tracé de leur apparence singulière que la marque de l'imitation du modèle de leur «sainte tribu ». Daniel Arasse, dans ses études sur l'image de saint Bernardin de Sienne, a bien analysé le phénomène ${ }^{63}$. Il se reproduit avec les Observants de la génération suivante. C'est là qu'intervient Crivelli. Car c'est un spécialiste de l'image hagiographique franciscaine. Il exécuta deux prototypes d'images de franciscains morts en odeur de sainteté dans la Marche d'Ancône : Jacques de la Marche et Gabriele Ferretti d'Ancône. 
Fig. 25

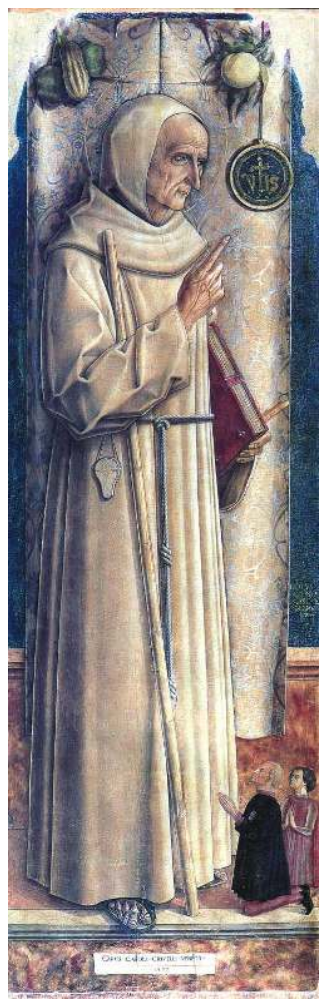

Carlo Crivelli, Bienheureux Jacques de la Marche, 1477, détrempe sur bois, 195 x 61 cm. Paris, Musée du Louvre. DR

Le B. Jacques de la Marche du Louvre, signé et daté de 1477 (fig. 25),est la première image connue du frère mineur, mort en 1476. Le culte du bienheureux Jacques était important à Ascoli, où il avait fait ses études et avait séjourné de nombreuses fois. Le frère Jacques étant mort à Naples, à défaut de corps, les franciscains d'Ascoli voulurent une image de substitution. Les petits donateurs agenouillés, en prière, aux pieds du bienheureux, indiquent sans doute une commande privée, un tableau votif. Mais l'image servit de point de départ à une tradition iconographique locale vivace ${ }^{64}$. Crivelli peignit plusieurs fois le frère mineur, notamment dans la pala de Lisbonne(fig. 26): représentant une Vierge de Miséricorde, ce retable, peint en temps de peste, ornait la chapelle spécialement construite par la Commune d'Ascoli et le Tiers ordre franciscain à la SS. Annunziata; œuvre votive qui montrait que si Jacques de la Marche était devenu le nouveau saint patron d'Ascoli, Crivelli était devenu son peintre officiel. Or, pour « inventer » la figure du bienheureux Jacques, Crivelli s'est inspiré des représentations de saint Bernardin (fig. 27). L'imitation spirituelle passe, dans les images de Crivelli, en imitation physique: même figure ascétique, même maigreur, même symbole, le médaillon du Nom de Jésus, dont Jacques de la Marche, comme les autres disciples du saint siennois, avait fidèlement repris l'usage ${ }^{65}$. 
Fig. 26

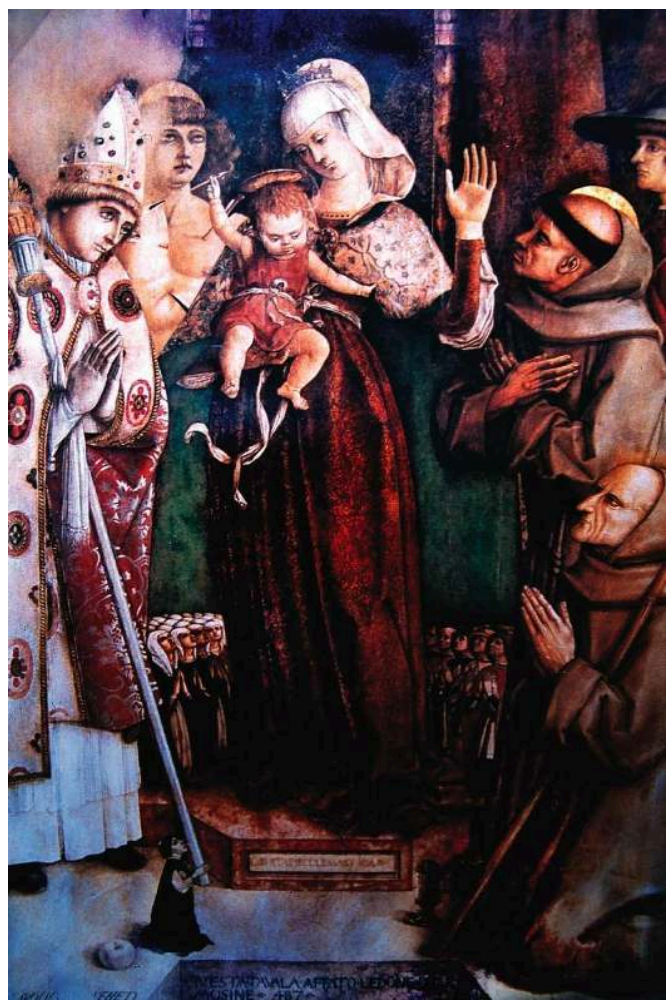

Carlo Crivelli, Vierge de Miséricorde, 1487, détrempe sur bois, 160 x 107 cm. Lisbonne, collection privée. DR 
Fig. 27

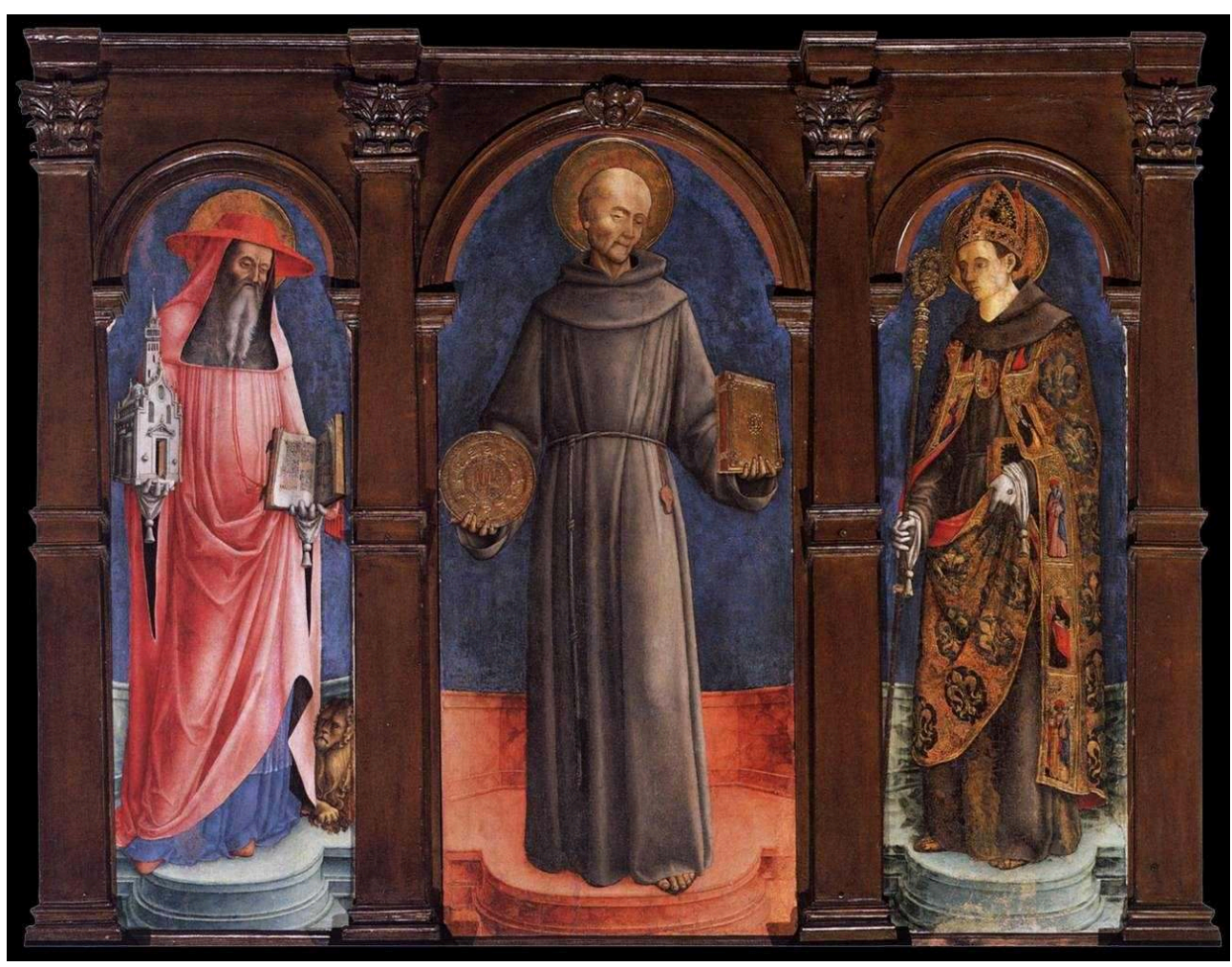

Antonio Vivarini, Saint Bernardin de Sienne entre saint Antoine abbé et saint Louis de Toulouse, 1451-56, détrempe sur bois. Venise, S. Francesco della Vigna. DR

Ancône est la ville la plus importante et la plus riche de la région. Elle a le statut de la «libertas ecclesiastica», et les familles qui la dirigent sont anciennes et puissantes. Parmi les principales, les Ferretti, qui compta dans ses rangs, au Quattrocento, un représentant majeur de l'ordre franciscain: fra Gabriele (mort en 1456) ${ }^{66}$. Celui-ci suscitera un culte local, qui culminera avec sa béatification en 1753. Le tableau de Crivelli, la Vision du B. Gabriele Ferretti (fig. 28), est probablement une commande due au neveu du bienheureux, Bernardino Ferretti, gardien du couvent fondé par son illustre oncle. Celui-ci désirait orner son tombeau nouvellement érigé, après approbation papale et une série de travaux d'embellissement du couvent et de l'église, en grande partie financés par la sœur de Bernardino ${ }^{67}$. Le tableau de Crivelli devait servir tout simplement d'image cultuelle d'un franciscain important dont la famille voulait défendre et valoriser la mémoire. 
Fig. 28

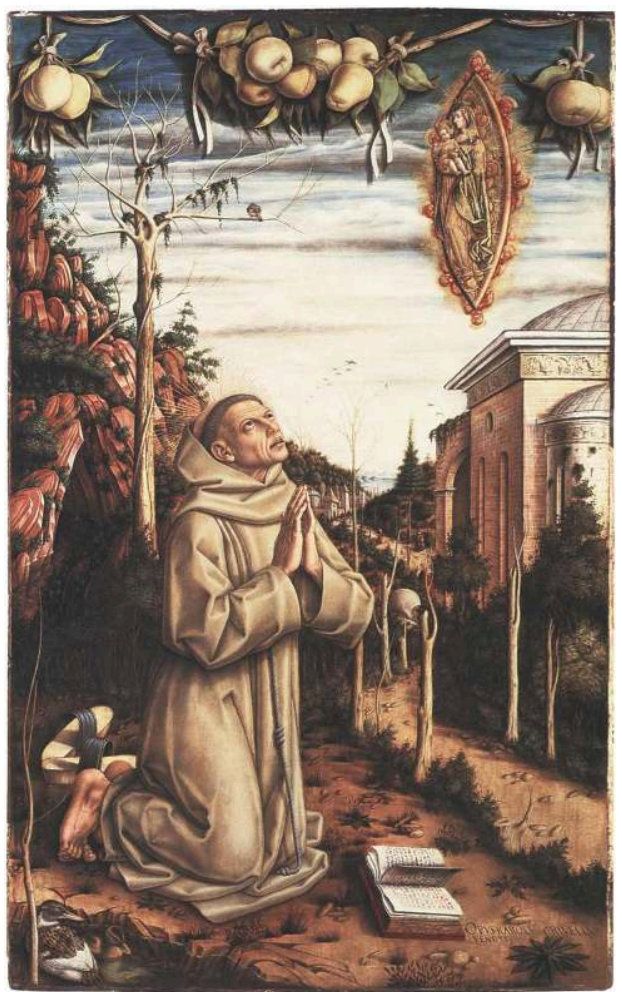

Carlo Crivelli, Vision du bienheureux Gabriele Ferretti, v. 1489, détrempe et huile sur bois, 141 x $87 \mathrm{~cm}$ Londres, National Gallery. DR

Le portrait qu'en fait Crivelli, dans le tableau qui devait surmonter son tombeau, le montre dans l'attitude significative du mystique: l'extase devant une vision de la Vierge. Or la représentation d'un franciscain, en pleine vision de la Vierge, est très rare à cette époque. Un autre tableau cependant a pu servir de précédent : c'est un retable (fig. 29), peint par Giacomo da Recanati, qui représente la Vierge à l'Enfant dans une mandorle entourée de saints et avec, agenouillé devant elle, le bienheureux Pietro da Monticello (re-baptisée Treia), à moins qu'il ne s'agisse du bienheureux Corrado d'Offida ${ }^{68}$. La donnée narrative est beaucoup moins présente dans ce tableau que dans celui de Crivelli : on aurait plutôt affaire à une Vierge en trône, que l'on aurait remplacé par une mandorle, avec un donateur auquel se serait substitué le bienheureux. 


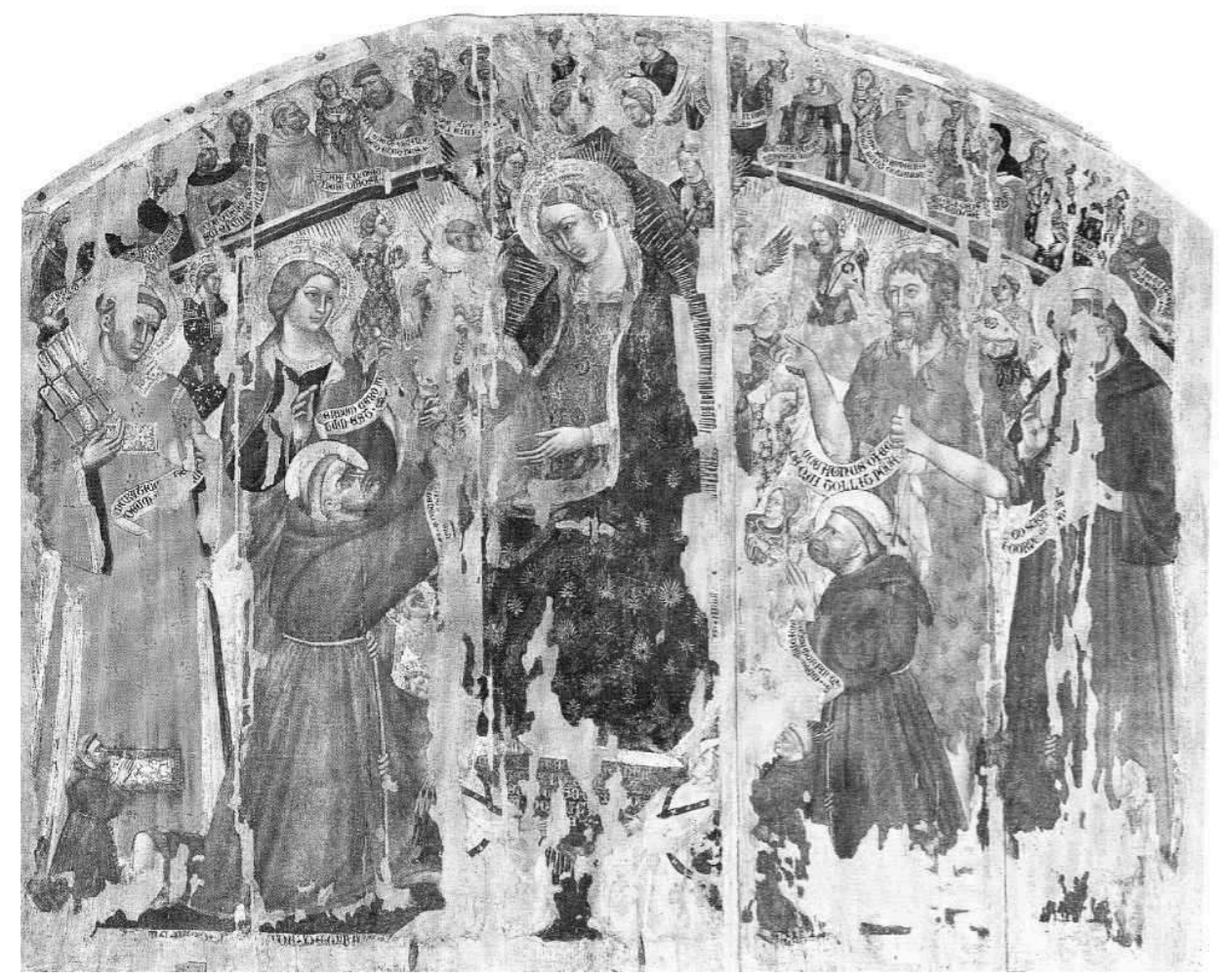

Giacomo da Recanati, Vision du bienheureux Pietro da Treia ou Corrado d'Offida, v. 1440-45, détrempe sur bois, $233 \times 202 \mathrm{~cm}$. Treia, Collegiata. DR

On sait par un récit des Fioretti ${ }^{69}$ que fra Corrado d'Offida (mort en 1306) est l'un des seuls franciscains connus qui ait précocement bénéficié d'une telle vision de la Vierge. Il aurait vu la Vierge lui apparaître près de Forano (Appignano aujourd'hui), dans le diocèse d'Osimo, «espionné » par son compagnon Pietro da Monticello. Le tableau de Giacomo da Recanati fut peint pour la chapelle de la "Madone des anges ", édifiée à l'endroit de l'apparition ${ }^{70}$. Or la tradition locale veut que fra Corrado soit passé au couvent d'Ancône, y ait laissé son empreinte spirituelle, celle d'un courant rigoriste orienté vers l'anachorétisme et le mysticisme ${ }^{71}$. Les Fioretti sont le texte de référence de l'observance, qui consacre plusieurs chapitres aux "Spirituels» de la Marche d'Ancône, dans un contexte polémique avec les conventuels ${ }^{72}$. Tel est donc peut-être le modèle spirituel de Gabriele Ferretti : une pratique monastique où la prière assidue, la dévotion à la Vierge, orientent plus le moine vers le mysticisme que vers la prédication ou les charges publiques. D'ailleurs fra Gabriele est aussi connu pour avoir refusé la mission d'évangélisation de la Bohême que lui proposait le pape. Pour le dire brièvement, la sainteté du bienheureux Gabriele ne s'exprimait pas par la prédication, mais par sa capacité à avoir des visions, à l'instar de son probable modèle, Corrado d'offida. Le tableau de Crivelli construit, par l'image, la même généalogie locale.

Dans le milieu religieux qui commandait ses tableaux à Crivelli, la logique hagiographique de l'imitation était pleinement opératoire. La communauté des moines se fonde autour d'un modèle auquel chacun de ses membres s'identifie. Mais est-il pertinent, du point de vue de l'histoire sociale, de l'appliquer à un groupe laïc (les crivellesques), et même, un groupe informel, qui n'apparaît que par la comparaison 
stylistique et non par l'existence d'archives indiquant une administration, une vie de groupe?

D'abord, il faut remarquer que le principe d'imitation grégaire, évident dans les communautés monastiques, s'élargit, aux $\mathrm{xIV}^{\mathrm{e}}-\mathrm{xv}^{\mathrm{e}}$ siècles, aux communautés laïques. Je parle des groupes de pénitents qui, de procession en procession, se flagellent en public, surtout dans les moments de crise comme pendant la Peste Noire ou le Grand Schisme au XIV ${ }^{\mathrm{e}}$ siècle ; je parle des confraternités qui se multiplient depuis le XIII ${ }^{\mathrm{e}}$ siècle jusqu'à devenir une organisation sociale banale au $\mathrm{Xv}^{\mathrm{e}}$ siècle : tout le monde fait partie d'une confraternité, celle de l'église de sa paroisse, celle de son quartier, celle de sa corporation $^{73}$. Ce à quoi il faut rajouter aussi les Tiers ordres, c'est-à-dire les groupements de laïcs intégrés aux ordres mendiants, qui se répandent à partir du XIV ${ }^{\mathrm{e}}$ siècle, sans avoir été prévus dans les règles fondatrices ${ }^{74}$. Les sœurs et les frères du Tiers ordre bénéficiaient par contiguïté des prières, de la dévotion des moines, en échange de donations régulières (ou de promesse de legs post mortem). Par exemple, à la SS. Annunziata d'Ascoli, la chapelle votive consacrée à Jacques de la Marche en 1486 était entretenue par les sœurs du Tiers ordre franciscain ${ }^{75}$. Ceci explique que dans le tableau de Crivelli, la Vierge de Miséricorde (fig. 26), qui ornait le maître-autel de la chapelle, les femmes soient représentées à droite de la Vierge, et non à gauche, comme d'ordinaire : probablement que les sœurs contribuèrent en bonne partie au paiement du tableau.

62 Cette multiplication des communautés, basées sur un modèle religieux, où chaque membre du groupe est lié par le sentiment de faire partie d'une même famille, imite le même modèle identificatoire, est typique d'une époque, d'une société qui développe un ethos immanentiste, privilégiant la proxémie des rapports affectifs entre ses membres. C'est du moins ce qui ressort de la lecture de Michel Maffesoli. Celui-ci appelle «tribalisme » un fonctionnement de la société par groupes réduits qui trouvent leur cohérence, leur identité, autour d'un chef (par exemple le leader charismatique d'une secte, ou bien une chanteuse avec ses fans). La vénération du chef et la volonté de lui ressembler font fonctionner ces groupes. Maffesoli, qui analyse un tel tribalisme dans les sociétés occidentales contemporaines, voit dans ce phénomène la dissolution de l'individualisme dans le communautarisme ${ }^{76}$ et la baisse d'importance de facteurs identitaires généraux et abstraits de cohésion sociale du type la Patrie ou les Droits de l'Homme, un besoin de repli identitaire sur un terrain mieux connu, plus restreint (la communauté, au sens du communautarisme), une façon de concevoir l'éthique sociale non en fonction d'un droit moral général, mais de la satisfaction de besoins personnels :
«[...] on est confronté à un primum relationis, c'est-à-dire qu'au-delà ou en deçà de l'idéal, de l'idéologie, de la science, du service public, de la démocratie, sans parler d'autres valeurs plus particulières comme le socialisme, le libéralisme, le marché, le social, ou tant d'autres entités que l'on mettra en avant pour légitimer une pratique, ce qui va prévaloir c'est l'implacable loi tribale qui façonnera la pensée et l'action en fonction de l'appartenance groupale autour d'un héros éponyme ${ }^{77}$."

Maffesoli voit dans cette conception sensible, émotionnelle, du social, une certaine forme de religiosité : on ne vénère pas un dieu lointain qui promet la jouissance pour plus tard, mais des dieux locaux, des « dieux immanents », en chair et en os ${ }^{78}$.

On voit alors pourquoi la société crivellesque relève du fonctionnement tribal analysé par Maffesoli. Crivelli a pu tellement influencer la société des peintres de son 
environnement immédiat car il faisait office de chef de secte; il suscitait la même vénération auprès de ses collègues et disciples que celle qu'il voulait lui-même produire sur les spectateurs de ses tableaux.

Un autre point permet de compléter le tableau comparatif de la «tribu » contemporaine analysée par Maffesoli et de la société crivellesque. Pour le sociologue, le fonctionnement tribal des groupes sociaux, où l'affectif l'emporte sur le moral, favorise l'analogie avec le corps : ces tribus sont comme des organismes, des «corps sociaux » où chaque membre pense appartenir à un tout vivant. Or, au Xve siècle, une métaphore du corps social est pensée et utilisée couramment : le corps mystique.

Depuis le $\mathrm{xII}^{\mathrm{e}}$ siècle, cette métaphore paulinienne est devenue importante dans les discours politiques de l'Église et des États laïcs, destinée à figer dans un ordre transcendantal la hiérarchie sociale et à justifier ainsi la domination de ceux qui exercent le pouvoir ${ }^{79}$. Mais du temps de Crivelli, l'idée du corps mystique s'est étendue à tous les niveaux de la société. Un juriste $\mathrm{du}_{\mathrm{XV}}^{\mathrm{e}} \mathrm{s}$. distingue ainsi cinq corps mystiques qui s'emboîtent : le village, la ville, la province, le royaume et le monde; chez un autre auteur, le peuple lui-même devient un " corps mystique $»^{80}$. Comment dire autrement que l'existence collective est pensée comme unie par un lien sacré, comment mieux dire l'union de la vie mondaine et de la vie spirituelle? Ce «corporatisme» ou " corporéisme ${ }^{81}$ se déploie à de multiples échelles : l'individu fait toujours partie de plusieurs groupes, la famille, le corps de métier, la "corporation» au sens strict, la confrérie, le quartier, etc., jusqu'au sur-groupe que constitue le Corps Mystique par excellence, l'Église ${ }^{82}$. Les fêtes politico-religieuses qui jalonnent la vie de la cité peuvent, de ce point de vue, être considérées à la fois comme des occasions pour chaque groupe social de (se) manifester (les processions manifestent visuellement un classement du corps social en membres communautaires bien distincts) et un moyen de solidifier, de façon plus général, le lien social qui soude l'ensemble de la communauté83. Bien sûr, la famille constitue un groupe privilégié dans cette organisation sociale, dans la mesure où les rapports généalogiques et les jeux d'alliance créent de puissants liens affectifs. Mais la «famille» italienne, au $\mathrm{xv}^{\mathrm{e}}$ siècle, a plus de parenté avec la gens romaine qu'avec la famille nucléaire moderne: elle comprend également tous les serviteurs, les employés, les relations de travail, bref toute la « clientèle » qui gravite autour du noyau familial ${ }^{84}$. Et par ailleurs, la famille est un clan politique qui, dans le régime oligarchique des communes, est un soutien plus qu'indispensable pour accéder au pouvoir ou s'y maintenir ${ }^{85}$. Le clan familial, structure dominante dans l'Italie du Quattrocento, est bien, écrit Jacques Heers, une «tribu », au sens de Maffesoli :

« Les hommes appartiennent avant tout à leur tribu ; ils en attendent, pour les uns, un surcroît de puissance, pour les autres, une protection et des secours. En tout cas, voici un exemple frappant et indiscutable de groupes sociaux, ayant une vie propre, maintenus et solidaires par quantité de liens de toutes sortes et en particulier par une véritable cohabitation à l'intérieur de la ville, unissant souvent leurs efforts, gardant conscience d'une certaine communauté spirituelle ; ces groupes comptent à la fois des grands seigneurs fonciers, guerriers et politiques, des riches marchands ou banquiers, des petits négociants, des hommes de peu, des esclaves affranchis et des pauvres mêmes ${ }^{86}$. "

On comprend qu'Alberti fasse de la famille à la fois le garant de la prospérité économique et le synonyme de la république ${ }^{87}$. Ainsi le pouvoir politique, autrefois communal, est-il confisqué par des familles un peu partout en Italie - familles qui au départ ne sont pas en situation sociale de gouverner : des marchands (les Médicis ${ }^{88}$ ), des 
mercenaires (les Sforza) ; même le pouvoir pontifical tend à devenir héréditaire, c'est le triomphe du népotisme (de Sixte IV à Léon $\mathrm{x}$, en passant par les Borgia père et fils) ${ }^{89}$.

L'assimilation de la tribu sociale au corps mystique oblige donc à s'écarter d'une idée strictement biologique du corps. Dans le Corps Mystique, la tête (le chef) est aussi le corps lui-même, à l'instar du Christ : chef de l'Église et corps de l'Église, dans la mesure où les fidèles, incorporant l'eucharistie, se fondent dans le Christ. Allons jusqu'au bout de notre idée : Crivelli aurait donc, toutes proportions gardées, dans la corporation informelle des peintres de la Marche d'Ancône le rôle du Christ dans l'organisme chrétien, dans la théologie du corps mystique: il le dirige et le constitue stylistiquement.

\section{Le corps mystique de l'artiste}

70 Ainsi, chez les artistes comme chez les religieux, apparaît une forme de parenté hybride, une filiation non généalogique, non biologique, où la ressemblance n'est pas subie mais où elle est désirée; où l'imitation ne produit pas seulement une duplication du même, mais un écart, puisque imiter un modèle est une manière de se différencier de soi. En rabattant l'imitation sur la ressemblance, en les opposant unilatéralement à la différence et au devenir, Deleuze et Guattari se simplifiaient un peu trop la tache. Le cas Crivelli montre qu'il ne suffit pas d'opposer la filiation et l'alliance pour comprendre la création : il faut distinguer plusieurs formes de filiation et d'alliance. Sous un certain angle, celui de la création crivellesque par exemple, alliance et filiation peuvent se prolonger l'une dans l'autre, quand l'alliance génère une bande, une tribu, une famille artistique ou spirituelle.

71 Un petit tableau de Crivelli pourrait s'interpréter comme l'allégorie de la bande de Crivelli et des crivellesques, rapports pensés par analogie avec ceux qu'entretiennent les moines et leur abbé, les saints et le Christ. Un tableau qui représente une Cène mais qu'on pourrait surnommer « La tribu Crivelli » (fig. 30).

Fig. 30

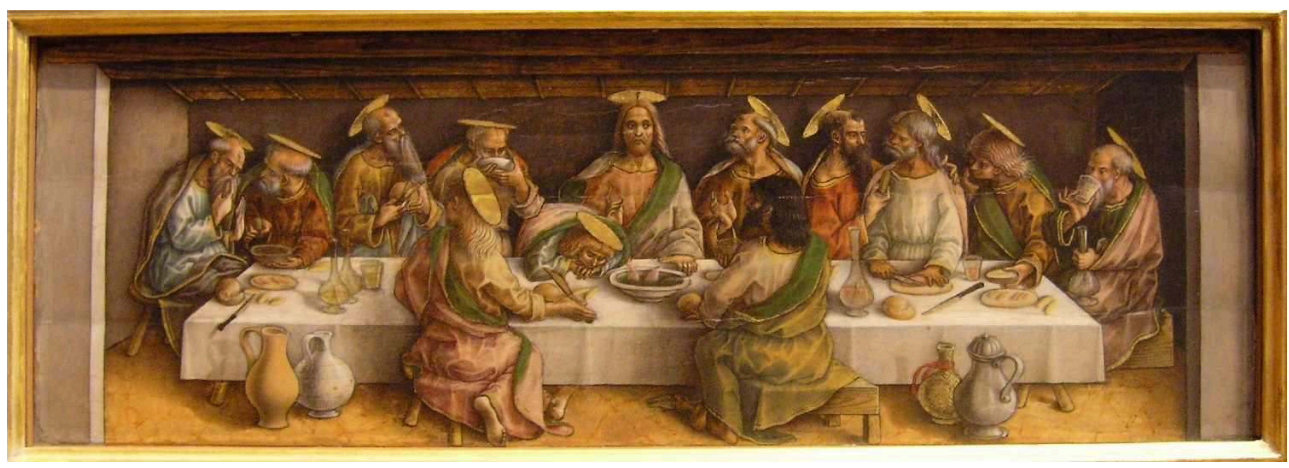

Carlo Crivelli, Cène, 1482, détrempe et huile sur bois, 26,7 x 75,3 cm. Montréal, Museum of Fine Arts. $\mathrm{DR}$

72 D'après ses dimensions, il devait faire partie du polyptyque de $\mathrm{S}$. Domenico à Camerino (1482), dont on connaissait les deux panneaux de prédelle latéraux, mais pas celui du centre. Une Cène dans la prédelle d'un retable, rien de plus normal au Quattrocento : la messe n'est-elle pas un rappel du premier repas eucharistique? En revanche, anormal 
est l'objet que tiennent plusieurs apôtres. Un objet vert en forme de tube. Un concombre? Et pourquoi pas : devant Jésus se trouve un petit bol rempli de fenouils ; d'autres apôtres coupent du salami ou du pain, d'autres préfèrent boire. Un apéritif, en somme. Voilà le concombre crivellesque intégré au repas eucharistique : un apôtre à l'extrême gauche le goûte, son voisin le tient dans la main, comme s'il attendait la réaction du premier avant de se lancer; de l'autre côté, un apôtre ressemblant à saint Paul lui-même tend à son voisin un concombre en le regardant fixement, l'air de dire : ils sont bons, tu verras. Mais ce n'est pas cette ambiance sympathique et méridionale qui m'intéresse ici. C'est ce que fait Crivelli, en plaçant "son" concombre entre les mains des apôtres, comme s'ils se partageaient non plus le pain, le corps du Christ, mais le corps du peintre. Très discrètement, comme pour lui-même (car les spectateurs de l'époque ne pouvaient voir que difficilement un détail aussi minuscule, derrière tous les objets posés sur l'autel), Crivelli offre aux apôtres - aux spectateurs, à ses collègues peintres - son objet fétiche, la métonymie de son corps, c'est-à-dire son art, à l'instar du Christ qui offre lui aussi métonymiquement le pain à la place de son corps. La relation entre le peintre et le spectateur s'en trouve sacralisée. Ce panneau curieux semble dire : Crivelli est à la peinture ce que le Christ est à la divinité : il en est l'incarnation.

Dans l'histoire des progrès du statut de l'auteur, du développement du «culte » de l'artiste, on aurait tort de négliger Carlo Crivelli et ce que représente sa peinture : un maillon entre l'époque de l'image et l'époque de l'art, entre la dévotion suscitée par le charisme du saint et l'admiration provoquée par l'aura de l'humain créateur.

\section{NOTES}

1. Gilles DeLeUZE et Félix GUATTARI, Mille plateaux. Capitalisme et schizophrénie 2, Paris, Minuit, 1980, p. 291.

2. Le passage cité ci-dessus s'inscrit dans un sous-chapitre de Mille plateaux intitulé «Souvenirs d'un bergsonien ".

3. Sur l'opposition entre l'être et le devenir dans l'histoire de la philosophie, lire Henri BERGSON, L'Évolution créatrice [1907], Paris, P.U.F., 154e édition, 1981, p. 298 sq.

4. Michel de montAigne, Les Essais, éd. P. Villey [1924, nouvelle. éd. 1965], Paris, P.U.F., 1988, II, 37, p. 763.

5. Didier LETT, («L'“expression du visage paternel”. La ressemblance entre le père et le fils à la fin du Moyen Âge : un mode d'appropriation symbolique ", Cahiers de recherches médiévales (XIII $X V^{e}$ s.), vol. IV, 1997, p. 115-25 ; Bernard VERNIER, «La théorie populaire des ressemblances familiales à Karpathos ", Actes de la recherche en sciences sociales, vol. 78, 1989, n² 2, p. 18-23; Eduard FRUNZEANU, "Le corps et la ressemblance parentale (XII ${ }^{\mathrm{e}}-\mathrm{XVI}^{\mathrm{e}}$ siècles) ", novembre 2009, consultable en ligne $:$ http://halshs.archives-ouvertes.fr/halshs-00430558/en/.

6. Lire les commentaires de René LEFEBVRE, «Individu, espèce et ressemblance dans la théorie aristotélicienne de la génération animale », Revue de métaphysique et de morale, vol. 100, 1995, n 4, p. 533-62. 
7. C'est le médecin italien Dino del Garbo (mort en 1327) qui fera explicitement l'association entre les théories aristotéliciennes de la génération et de la création. Dino DEL GARBO, Scriptum super librum De natura fetus Hypocratis, Venise, 1502, f. 76rb - 77va ; cité par E. FRUNZEANU, «Le corps et la ressemblance parentale ", op. cit., p. 13.

8. Plusieurs auteurs évoquent la vis imaginativa comme cause de dissemblance extérieure : saint Augustin est l'auteur d'une anecdote reprise à foison au Moyen Âge selon laquelle, un enfant ne ressemblant pas du tout à son père, on trouva une image que la mère avait probablement regardée pendant sa conception, ce qui permit de la disculper.

9. Id., La Pensée et le mouvant [1938], Paris, P.U.F., 13éd. « Quadrige », 1998, p. 99-100.

10. Michel de MONTAigne, Apologie de Raymond Sebond, in Id., Les Essais, op. cit.,II, 12, p. 601-603.

11. Henri BERGSON, La pensée et le mouvant, op. cit.,p. 116.

12. Giorgio VASARI, Les Vies des meilleurs peintres, sculpteurs et architectes, trad. dirigée par A. CHASTEL, Paris, Berger-Levrault, 1981-87,vol. I, p. 232.

13. La perspective de Vasari est identitaire et courtisane: dans la première Dédicace au duc Cosme de Médicis, Vasari écrit de ces artistes dont il écrit les vies glorieuses : «Presque tous étaient toscans, la plupart florentins, et beaucoup d'entre eux ont été soutenus et stimulés à l'ouvrage avec toutes sortes d'avantages et d'honneurs par vos très illustres aïeux : on peut donc dire que votre pays, et même votre maison fortunée ont vu renaître ces arts qui ont rendu au monde noblesse et beauté. » (ibid., vol. I, p. 41).

14. Ibid., vol. II, p. 23. Sophie LUGON-MOULIN, Naissance et mort de l'artiste. Recherches sur les Vies de Vasari, Thèse de Doctorat, Université de Fribourg, 2005, p. 118.

15. Giorgio VASARI, Les Vies des meilleurs peintres, op. cit., vol. II, p. 255.

16. Notons tout de même que le propos de Vasari ne se limite pas à identifier les caractères propres à chaque manière locale, comme ont pu le faire des historiens de l'art plus récents ; Vasari cherche avant tout à décrire le progrès des arts, progrès qui implique le dépassement du maître par l'élève et l'idée d'une imitation qui produit de la différence. Sur ce point, je me dois de renvoyer à un autre article, «Le portrait craché », en préparation.

17. André CHASTEL, «L'aria: théorie du milieu à la Renaissance », in Id., Fables, Formes, Figures, Paris, Flammarion, 1978, vol. I, p. 393-405 (p. 393-94).

18. Giorgio VASARI, Les Vies des meilleurs peintres, op. cit., vol. V, p. 220-21.

19. Ibid., vol. III, p. 17-25. Et aussi dans la Préface générale: les artistes « ont pu voir comment l'art, dès son origine, a atteint les sommets les plus élevés, et comment, d'un degré si haut, il est tombé dans la plus sombre ruine. Ils ont ainsi perçu sa nature qui, comme le corps humain, comporte naissance, croissance, vieillissement et mort. Ils pourront maintenant mieux apprécier sa renaissance, sa remontée et sa perfection actuelle. » (ibid., vol. I, p. 233).

20. Henri focillon, Vie des formes [1943], Paris, P.U.F., $7^{\mathrm{e}}$ éd. « Quadrige », 2000, p. 25.

21. C'est l'approche que le grand spécialiste italien de Crivelli, Pietro ZAMPETTI, a toujours privilégiée, en organisant notamment en 1961 une exposition intitulée Crivelli e i Crivelleschi, Venise, 10 juin - 10 octobre 1961, catalogue de l'exposition, Venise, Alfieri, 1961.

22. Pour les données biographiques, je renvoie aux monographies de Pietro zAMPETTI, Carlo Crivelli, Florence, Nardini, 1986, p. 11-17, 311-17, et de Ronald Lightbown, New Haven \& Londres, Yale University Press, 2004.

23. HUGUES DE SAINT-VICTOR, Didascalicon, 760, cité par Edgar De Bruyne, Études d'esthétique médiévale [1946], Paris, A. Michel, 1998, vol. I, p. 755.

24. Claude LÉVI-STRAuSS, La Pensée sauvage [1962], Paris, éd. Pocket, 1990, p. 30-31.

25. Leon Battista ALBERTI, Profugiorum ab erumna libri, éd. G. Ponte, Gênes, Tilgher, 1988, p. 80-83.

26. Giorgio VASARI, Les Vies des meilleurs peintres, op. cit., vol.IV, p. 305. 
27. Sur ce peintre de Zadar, lire Ivo PETRICIOLI, « Orme di Carlo e Vittore Crivelli a Zara : l'opera pittorica di Pietro Jordanic e le testimonianze archivistiche », in S. PAPETTI (dir.), Vittore Crivelli e la pittura del suo tempo nel Fermano, Milan, F. Motta, 1997, p. 37-41.

28. Sur la signification politique de ce tableau, T. GOLSENNE, «L'Annonciation de Crivelli et le problème de l'ornement ", Studiolo, n 1, 2002, p. 149-76 (p. 153-57).

29. Pietro ZAMPETTI, Carlo Crivelli, op. cit.,p. 317.

30. Ce retable, attribué aujourd'hui à Giovanni Angelo d'Antonio et daté des environs de 1455, était conservé dans l'église de l'Observance de Spermento près de Camerino. Lire à ce sujet Andrea DI LORENZo, « Maestro dell'Annunciazione di Spermento (Giovanni Angelo d'Antonio ?) », in A. DE MARCHI (dir.), Pittori a Camerino nel Quattrocento, Milan, F. Motta, 2002,p. 294-319.

31. Ainsi Michel Laclotte remarque-t-il que «le succès venu, Crivelli (comme Bartolomeo Vivarini à Venise) commercialisa passablement sa production, qu'il en répéta non sans rhétorique les effets admirés. [...] Une telle attitude lui permet d'exprimer les accents de l'introspection, mais explique en même temps les défaillances ou les redites d'une inspiration parfois sclérosée. [...] Toute sa vie, il continuera de puiser dans le catalogue du 'bazar' padouan, lui empruntant colonnes de marbre et bas-reliefs antiques, grappes de fruits et de légumes, tapis rutilants et joyaux précieux. [...] Pendant cette période, Crivelli, isolé, vit sur lui-même, utilise le répertoire heureusement fort riche de ses années de formation, et ignore délibérément l'évolution de la peinture contemporaine. » (Michel LACLOTTE, « Mantegna et Crivelli », L'œil, nº 85, janvier 1962, p. 28-37, 92-93 [p. 92-93]).

32. On pourrait analyser l'œuvre de Raphaël de ce point de vue de l'alliance: empruntant pendant ses années de formation le style des autres (Perugino, Léonard, Michel-Ange), jusqu'à former son style universel.

33. Aby WARBURG, Essais florentins, trad. S. Muller, Paris, Klincksieck, 1990, p. 108-10, 126, et Georges DIDI-HUBERMAN, L'Image survivante. Histoire de l'art et temps des fantômes selon Aby Warburg. Paris, Éd. de Minuit., p. 51-102.

34. Michael BAXANDALL, Les humanistes à la découverte de la composition en peinture, 1340-1450 [1971], trad. M. Brock, Paris, Éd. du Seuil, 1989, p. 146.

35. Par exemple Lightbown y voit une figure de la Résurrection de Jésus, par association avec l'arbre à courges dont la Septante (mais pas la Vulgate, qui parle d'un arbre à ricin) qui aurait abrité Jonas du soleil après son expulsion de la baleine - une exégèse qu'on ne trouve chez aucun auteur médiéval, et pour cause : ils ne lisaient que la Vulgate (Ronald LIGHTBOwN, Carlo Crivelli, op. cit., p. 149).

36. Alessandro DE MARCHI (dir.), Pittori a Camerino nel Quattrocento, op. cit., p. 356-61. Si l'on accepte l'attribution au même peintre de l'Annonciation de Spermento et de la fresque de la Vierge à l'Enfant, ainsi que leurs datations supposées, alors dans un cas Crivelli se serait inspiré du modèle de Camerino, dans l'autre il en aurait été la source d'inspiration.

37. Baldassare ORSINI, Descrizione delle pitture, sculture, architetture ed altre cose rare dela insigne città di Ascoli, Pérouse, Baduelliana, 1790, p. 44.

38. Sur ces problèmes d'attribution, lire Pietro ZAMPETTI, Carlo Crivelli, op. cit., p. 304-5. Au frère âné reviendraient le Saint Nicolas, le Saint Michel et les quatre saints du registre supérieur; au frère cadet, les deux panneaux centraux, le Saint Jean-Baptiste, le Saint Martin et la prédelle.

39. Olivier BoulnoIs, Au-delà de l'image. Une archéologie du visuel au Moyen Âge ( $V^{e}-X V I^{e}$ siècle), Paris, Éd. du Seuil, 2008, p. 45-46.

40. Alain BOUREAU, L'Événement sans fin. Récit et christianisme au Moyen Âge, Paris, Les Belles Lettres, 1993, p. 11.

41. Saint AUGUSTIN, Confessions, VII, $x, 16$, in Id., Euvres, vol. I, trad. L. Jerphagnon. Paris, Gallimard («La Pléiade»), p. 918 ;cité par Georges DIDI-HUBERMAN, Fra Angelico. Dissemblance et figuration [1990], Paris, Flammarion, 1995, p. 75-77. 
42. Olivier BoulnoIs, Au-delà de l'image, op. cit., p. 266.

43. André VAUCHEZ, "Saints admirables et saints imitables. Les fonctions de l'hagiographie ontelles changé aux derniers siècles du Moyen Âge? ", Collection de l'École Française de Rome, vol. 149, 1991, p. 161-72.

44. Id., Les Laïcs au Moyen Âge. Pratiques et expériences religieuses, Paris, Éd. du Cerf, 1987.

45. Alain BOUREAU, L'Événement sans fin, op. cit., p. 67.

46. Et de plus en plus au cours des «couches» hagiographiques successives, jusqu'au De conformitate beati Francisci ad vitam domini Iesu de BARTOLOMEO DA PISA (commencée 1385, approuvée par le Chapitre d'Assise 1399) ; cf. Raoul MANSELLI, "Agiografia francescana tra interpretazione teologica e reliogiosità popolare", in Agiografia nell'Occidente cristiano, secoli XIII-XV, Convegno Internazionale, Roma, 1-2 marzo 1979, Roma, Accademia Nazionale dei Lincei (« Atti dei convegni Lincei », 48), 1980, p. 45-56 (p. 49) et R. PACIOCO, Da Francesco ai "catalogi sanctorum». Livelli istituzionali e immagini agiografiche nell'ordine francescano (secoli XIII-XIV), S. Maria degli Angeli, ed. Porziuncula,1990, p. 87.

47. L'épisode des stigmates a mis longtemps à s'imposer et à être reconnu officiellement par l'Église: les dominicains y voyaient une nouveauté invraisemblable. Bien qu'on puisse être d'accord avec André Vauchez quand il remarque que cet épisode exceptionnel fait de François un être hors du commun, difficilement imitable, il n'en reste pas moins évident que le sens même de l'épisode est de constituer l'imitatio Christi comme un idéal de vie.

48. Johan HuizingA, Le Déclin du Moyen Âge [1919], trad. J. Bastin, Paris, Payot 1967, p. 235-36.

49. Sur les Observants franciscains, lire Mario FoIs, «Il fenomeno dell'Osservanza negli ordini religiosi tra il 1300 e il 1400. Alcune particolarità dell'Osservanza francescana », in G. CARDAROPOLI (dir.), Lettura delle fonti francescane attraverso i secoli: il 1400, Rome, Ed. Antonianum, 1981, p. 53-105.

50. Mario SENSI, Le Osservanze francescane nell'Italia centrale, secoli XIV-XV, Rome, Collegio S. Lorenzo da Brindisi, Istituto storico dei cappucini, 1985, p. 19-73 ; Id., Dal movimento eremetico alla regolare osservanza francescana. L'opera di Paoluccio Trinci, Assise, Porziuncula Edizioni, 1992.

51. Sur la séparation entre Conventuels et Observants, lire Gustavo PARISCIANI, I frati minori conventuali delle Marche (sec. XII-XX), Ancône, Curia prov. frati minori conventuali, 1982, p. 9-235.

52. Sur le charisme de Bernardin et sa canonisation, lire Daniel ARASSE, "Fervebat pietatate populus". Art, dévotion et société autour de la glorification de saint Bernardin de Sienne», Mélanges de l'École Francaise de Rome - Moyen-Âge et Temps Modernes, 89, 1977, n 1, p. 189-263.

53. Id., "Saint Bernardin ressemblant : la figure sous le portrait », in D. MAFFEI et P. NARDI (dir.), Atti del simposio internazionale cateriniano-bernardiniano, Siena, 17-20 aprile 1980, Sienne, Accademia senese degli Intronati, 1982, p. 311-32. Lire aussi Mario Alberto PAVONE, Iconologia francescana. Il Quattrocento, Todi, Ediart, 1988, p. 126-28.

54. Le médaillon comportant le trigramme "YHS » et que Bernardin brandissait pendant ses prêches, faisait apposer sur les portes et les murs des maisons, des palais, des églises, dont il guérissait les malades, et qui lui suscita des accusations d'idolâtrie. Lire G. GONNET, « S. Bernardino da Siena e la cosidetta “eresia" del Nome di Gesù », in F. D’EPISCopo (dir.), S. Bernardino da Siena predicatore e pellegrino, Galatina, 1985, p. 41-51. Sur la défense de Jacques de la Marche, Carlo DELCoRno, « Due prediche volgari di Jacopo della Marca a Padova nel 1460 ", Atti dell'Istituto Veneto di scienze, lettere ed arti - Classe di scienze morali, lettere ed arti, 128, 1970, p. 174-205 (p. 200-1).

55. Ainsi Jacques de la Marche prêchant à l'Aquila, raconte comment Bernardin, qui y prêchait peu de temps avant sa mort, vit apparaître une étoile au milieu du public : c'était le signe de sa mort prochaine. Panégyrique de Padoue, 1460, publié par Carlo DELCORNO, « Due prediche volgari di Jacopo della Marca a Padova nel 1460 », art. cit., p. 203 ; une étoile apparaitra à Jacques de la 
Marche de la même manière (Marino sGatToni, La Vita di S. Giacomo della Marca per Fra Venanzio da Fabriano, Zadar, convento S. Francesco, 1940, p. 159).

56. Ibid., p. 184.

57. Umberto PICCIAfuoco, La Vita di S. Giacomo della Marca (1393-1476) secondo gli antichi codici di fr. Venanzio da Fabriano (1434-1506), Monteprandone, Santuario «S. Giacomo - S. Maria delle Grazie ", 1977, p. 12.

58. Ibid., p. 16.

59. Chloé MAILLET, La Parenté hagiographique. D'après Jacques de Voragine et les manuscrits enluminés de la Légende dorée (c. 1260-1490), Thèse de Doctorat, ÉHÉSS, 2010.

60. Alain BOUREAU, L'Événement sans fin, op. cit., p. 125-29.

61. Maaike VAN DER LUGT et Charles de MIRAMON (dir.), L'Hérédité entre Moyen Âge et Époque moderne. Perspectives historiques, Florence, Sismel, 2008, p. 105-244.

62. Hans BeLting, Image et culte. Une histoire de l'image avant l'époque de l'art [1990], trad. F. Müller, Paris, Éd. du Cerf, 1998, p. 221-46.

63. Daniel ARASSE, « La figure sous le portrait », art. cit.

64. Thomas GOLSENNE, «"Tanta vertù et efficatia”. Aux origines d'un culte : le Bienheureux Jacques de la Marche de Carlo Crivelli ", in Mélanges de l'Ecole Française de Rome, Moyen Âge, 114, $\mathrm{n}^{\circ} 2$, p. 1067-93 ; Id., "Le culte du bienheureux Jacques de la Marche à travers les œuvres de Carlo Crivelli », in Silvano BRACCI (dir.), San Giacomo della Marca. Uomo di fede, studio e azione, convegno internazionale, Monteprandone, 24-25 novembre 2001, publié dans Picenum Seraphicum, XXI, 2002, p. 127-42.

65. Quelques différences sont à souligner : menton en galoche et cheveux blancs chez Bernardin, bâton de pèlerin chez Jacques de la Marche, et surtout, Nom de Jésus porté comme un disque pour le maître et suspendu comme un médaillon chez le disciple. Pour plus de détails, je renvoie le lecteur aux deux articlés cités dans la note précédente.

66. Sur les Ferretti au XV ${ }^{\mathrm{e}}$ s., lire Mario NATALUCCI, Ancona attraverso i secoli. Il Quattrocento, Città di Castello, Unione arti grafiche 1958, p. 90. Sur fra Gabriele, ibid.,p. 108-9.

67. Antonio TALAMONTI, Cronistoria dei frati minori della provincia lauretana delle Marche,Sassoferrato, Scuola tipografica francescana, 1938-41, p. 57-58; le chroniqueur Bernabei, qui rédige à partir de 1492, écrit qu'une tribune a été construite récemment pour augmenter la taille de l'église du côté de la chapelle du bienheureux et de la sacristie (Lazzaro BERNABEI, Croniche anconitane, éd. C. Ciavarini, Ancône, Tipografia del Commercio 1870, p. 54).

68. Germano LibERATI (dir.), Il Gotico internazionale a Fermo e nel Fermano, catalogo della Mostra, Fermo, 28 agosto-31 ottobre 1999, Livourne, Sillabe, 1999, p. 95-96 ; Giuseppe Cucco (dir.), Santuari nelle Marche. Regione Marche/Giunta Regionale, Università degli Studi di Urbino, 1996, p. 173.

69. Ernesto CAROLI (dir.), Fonti francescane [ $4^{\mathrm{e}}$ éd. 1990], Padoue, Ed. Messaggero Padova, 1996, p. 1547 ; repris dans le recueil hagiographique écrit dans les années 1470 par Giacomo oDDI, La Franceschina, ed. Nicola Cavanna, S. Maria degli Angeli, Tipografia Porziuncula, 1979, vol. I, p. 351-52.

70. Giuseppe cucco (dir.), Santuari nelle Marche, op. cit.,p. 172.

71. Antonio talAmonTI, Cronistoria dei frati minori, op. cit., vol. II, p. 31 ; Gustavo PARISCIANI, I Frati minori conventuali delle Marche, op. cit.,p. 106, 111.

72. Ernesto CAROLI (dir.), Fonti francescane, op. cit.,introduction, p. 263-64.

73. André VAUCHEZ, Les Laïcs au Moyen Âge, op. cit., p. 95-122, en particulier p. 101 : Tout se passe donc comme si, au Moyen Âge, les laïcs avaient été incapables de concevoir leur destinée spirituelle en dehors d'une référence à l'idéal et à la forme de vie des religieux. "

74. Giulia BARONE, «Gli ordini mendicanti », in André Vauchez (dir.), Storia dell'Italia religiosa, vol. I : l'Antichità e il Medioevo. Roma-Bari, Laterza, 1993, p. 347-73 (p. 371). 
75. Fondé en 1482, quand les franciscains de l'Observance emménagèrent à la SS. Annunziata. Un testament de 1506 mentionne un don de 24 ducats pour que la donataire soit enterrée dans la chapelle du Tiers ordre. Lire Antonio talAmontI, Cronistoria dei frati minori, op. cit., vol. I, p. 195.

76. Sur le lien entre esprit communautaire et fragmentation du moi en autant de masques, Michel MAFFESOLI, Le Temps des tribus. Le déclin de l'individualisme dans les sociétés postmodernes [1988], Paris, La table ronde, 2000, p. 25.

77. Ibid., p. 19.

78. Ibid., p. 84.

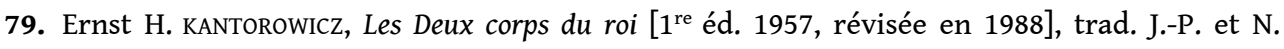
Genet, in Id., Euvres, Paris, Gallimard ("Quarto»), 2000, p. 643-1222 (ch. V, p. 793-802). Au Xv siècle, Nicolas de Cues se fait l'écho de cette théorie: «le pape, avec les patriarches et tous les chrétiens, constitue un tel corps unique, où divers sont les membres et où chacun se contente de son office afin que ne soit troublé l'ordre total. [...] Il est donc nécessaire que cette concordance consiste en une seule chose et en plusieurs, en un seul chef et en plusieurs membres. » (NICOLAS DE CUES, Concordance catholique, trad. R.Galibois, révisée par M. de Gandillac. Université de Sherbrooke, Centre d'Études de la Renaissance, 1977, I, 4, p. 56. Lire aussi III, 41, p. 406-9, où la métaphore corporelle est appliquée très littéralement à l'Empire.)

80. Ernst H. KANTOROWICZ, Les Deux corps du roi, op. cit.,p. 804.

81. Élisabeth CROUZET-PAVAN, Renaissances italiennes. 1380-1500, Paris, Albin Michel, 2007, p. 522, parle $d u$ «faire corps » qui se manifeste de diverses manières au Quattrocento, notamment à travers les confréries.

82. Jean-Claude sснмiтt, Le Corps, les rêves, les rites, le temps. Essais d'anthropologie médiévale, Paris, Gallimard, 2001, p. 356-59.

83. Élisabeth CROUZET-PAVAN, Renaissances italiennes, op. cit., p. 526-32.

84. Ibid., p. 419-26, 463-64.

85. Ruggiero ROMANO et Corrado VIVANTI (dir.), Storia d'Italia. I caratteri originali [1972], Turin, Einaudi, 1989, vol. I, p. 472.

86. Jacques HEERS, Le Clan familial au Moyen Âge [1971], Paris, P.U.F., 1993, p. 261, 263.

87. Leon Battista ALBERTI, I libri della famiglia, éd. R. Romano et A. Tenenti, nouvelle éd. F. Furlan, Turin, Einaudi, 1994, introduction, p. XXVII.

88. Jacques HEERS, Le Clan des Médicis. Comment Florence perdit ses libertés (1200-1500), Paris, Perrin, 2008.

89. Élisabeth CROUZET-PAVAN, Renaissances italiennes, op. cit., p. 512-13.

\section{RÉSUMÉS}

Étudier la peinture et la carrière de Carlo Crivelli du point de vue de la parenté se révèle riche de perspectives. En prenant comme point de départ l'interprétation formulée par Deleuze et Guattari de l'alliance comme forme de création, on cherche à repérer comment Crivelli a effectivement élaboré son style par alliage ou hétérogenèse. Mais Crivelli a lui-même suscité une «famille», celle des crivellesques, ces peintres qui ont imité son style pendant une trentaine d'années. Pour comprendre ce phénomène, un autre modèle s'impose: celui de l'imitation religieuse, de la «parenté hagiographique » ou de la « sainte tribu». 
Studying Carlo Crivelli's painting and carrier focusing on kinship appears full of perspectives. Starting from the interpretation formulated by Deleuze and Guattari about alliance as a form of creation, I try to analyse how Crivelli has actually elaborated his style through affinity or heterogenesis. But Crivelli has himself aroused a «family ", the crivelleschi : these painters who imitated his style during around thirty years. In order to understand this phenomenon, we need another model: religious imitation, « hagiographic kinship » or « holy tribe ».

\section{INDEX}

Index géographique : Italie

Index chronologique : XVe siècle

Keywords : alliance, Carlo Crivelli, filiation, Gilles Deleuze, hagiography, imitation, Marca di Ancona, painting, resemblance

Mots-clés : alliance, Carlo Crivelli, filiation, Gilles Deleuze, hagiographie, imitation, Marche d'Ancône, peinture, ressemblance

\section{AUTEUR}

\section{THOMAS GOLSENNE}

Thomas Golsenne, docteur en histoire de l'art, a fait son doctorat sur Carlo Crivelli et l'ornementalité au Quattrocento. Il est ancien pensionnaire de l'Académie de France à Rome et ancien professeur à l'École nationale des Beaux-Arts ; il enseigne actuellement l'histoire des arts visuels à la Villa Arson à Nice et est membre du comité de rédaction d'Images re-vues. Il a notamment co-publié une nouvelle traduction en français du De Pictura de Leon Battista Alberti (Paris, Seuil, 2004), co-dirigé La Performance des images (Bruxelles, Éd. de l'Université de Bruxelles, 2010), et publié divers articles sur l'ornementalité à la Renaissance ou dans l'art contemporain. Il prépare actuellement un essai monographique : Carlo Crivelli et le matérialisme mystique du Quattrocento. 